\title{
Numerical Modeling of Pressurization of Cryogenic Propellant Tank for Integrated Vehicle Fluid System
}

\author{
Alok K. Majumdar, ${ }^{1}$ Andre C. LeClair, ${ }^{2}$ and Ali Hedayat ${ }^{3}$ \\ Propulsion Systems Department, NASA Marshall Space Flight Center, Huntsville, Alabama 35812
}

\begin{abstract}
This paper presents a numerical model of pressurization of a cryogenic propellant tank for the Integrated Vehicle Fluid (IVF) system using the Generalized Fluid System Simulation Program (GFSSP). The IVF propulsion system, being developed by United Launch Alliance, uses boiloff propellants to drive thrusters for the reaction control system as well as to run internal combustion engines to develop power and drive compressors to pressurize propellant tanks. NASA Marshall Space Flight Center (MSFC) has been running tests to verify the functioning of the IVF system using a flight tank. GFSSP, a finite volumebased flow network analysis software developed at MSFC, has been used to develop an integrated model of the tank and the pressurization system. This paper presents an iterative algorithm for converging the interface boundary conditions between different component models of a large system model. The model results have been compared with test data.
\end{abstract}

\section{Introduction}

$\mathrm{F}_{\mathrm{v}}$ OR the past several years, United Launch Alliance has been developing a propulsion system called Integrated Vehicle Fluids (IVF) ${ }^{1}$ to improve the functional and reliability limits of upper stages for long-duration space missions. IVF uses boiloff propellants to drive thrusters for the reaction control system as well as to run small internal combustion engines (ICEs). The produced thrust is used for maneuvering the vehicle and to settle propellants aft during coast flight. The ICE produces shaft power that is partly converted into electrical power and partly drives hydrogen and oxygen compressors. Also, the ICE releases exhaust gases and heat. The exhaust gases contribute to vehicle settling and attitude control while the heat is mainly absorbed by the recirculating coolant. The vented boiloff propellants are heated in heat exchangers that use the warm coolant as the hot fluid. Then, the propellant tanks are pressurized with the heated gases leaving the heat exchangers.

Figure 1 shows a simplified schematic of the proposed IVF system. The pressurization system of the tank consists of a fluid loop with a compressor and heat exchanger instead of a helium tank in a conventional propulsion system. The compressor intakes propellant vapor from the tank ullage and drives it through a heat exchanger to heat it before it sends it back to the tank for pressurization. The heat exchanger receives heat from coolant of the ICE. The ICE provides power to the compressor and battery. The schematic does not include thrusters and the second propellant tank as this paper only focusses on numerical modeling of pressurization. Reference 1 provides more details of the entire system.

An efficient and robust system-level numerical model is essential in understanding the performance and optimizing the design of the IVF system. NASA Space Technology Mission Directorate's Evolvable Cryogenics project is currently testing the IVF system at NASA Marshall Space Flight Center (MSFC). The test program will be conducted in several phases. In phase A, a flight tank has been tested to measure boiloff and pressurization at various levels using both liquid hydrogen $\left(\mathrm{LH}_{2}\right)$ and nitrogen $\left(\mathrm{LN}_{2}\right)$. Phase $\mathrm{B}$ testing will include a pressurization loop consisting of a blower and the heat exchanger. In phase B testing, a compressor will be substituted with a blower and ICE coolant will be heated by an electric heater. In phase $\mathrm{C}$, the compressor will replace the blower and the coolant will be heated by the exhaust heat of the ICE which will run with the facility supply of hydrogen and oxygen.

One of the main tasks of this project is to develop a validated numerical model by comparing it with test data. The other purpose of this paper is to demonstrate a methodology of developing an integrated system and component model of the IVF system using the Generalized Fluid System Simulation Program (GFSSP). ${ }^{2}$

\footnotetext{
${ }^{1}$ Aerospace Engineer, Thermal and Combustion Analysis Branch, ER43, AIAA Senior Member.

${ }^{2}$ Aerospace Engineer, Thermal and Combustion Analysis Branch, ER43.

${ }^{3}$ Aerospace Engineer, Main Propulsion Systems Branch, ER22, AIAA Senior Member.
}

1

American Institute of Aeronautics and Astronautics 


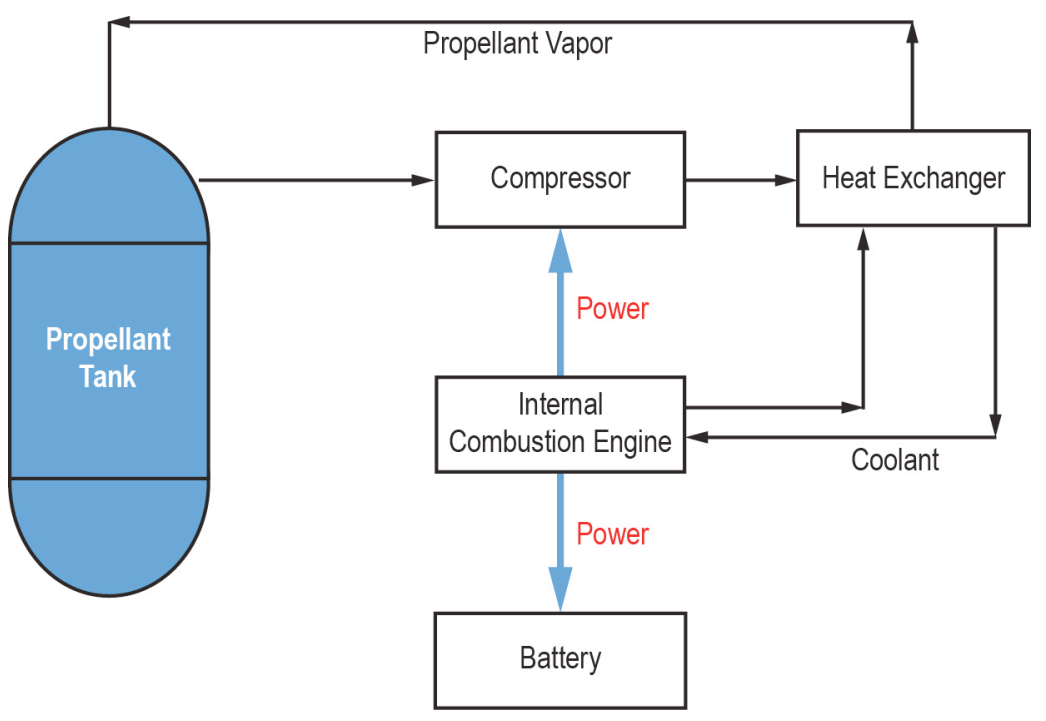

Figure 1. Simplified schematic of IVF system.

\section{Mathematical Formulation and Computer Program}

GFSSP is a finite volume-based network flow analysis program for analyzing thermofluid systems. A fluid network consists of boundary nodes, internal nodes, and branches to represent a fluid system. Boundary and internal nodes are connected through branches in series or parallel arrangements. At boundary nodes, pressures and temperatures are specified. Mass and energy conservation equations are solved in internal nodes. Flow rates are calculated in branches. A thermal system consists of solid and ambient nodes connected with conductors. A fluid and solid node are connected with a solid to fluid conductor to model conjugate heat transfer.

The mathematical closure is described in Table 1. GFSSP uses a pressure-based scheme as pressure is computed from the mass conservation equation. The mass and momentum conservation equations and thermodynamic equation of state are solved simultaneously by the Newton-Raphson method while energy conservation equations of fluid and solid are solved separately but implicitly coupled with the other equations stated above. The conservation equations are solved in conjunction with the thermodynamic equation of state. From the computed pressure and enthalpy at the nodes, all other thermodynamic properties including density, viscosity, and thermal conductivity are evaluated from built-in thermodynamic property programs. Vapor quality is calculated from liquid and vapor enthalpies at the node pressure for the saturated condition. Density and other thermophysical properties of the liquidvapor mixture are calculated as a function of vapor quality. Further details of the mathematical formulation and solution procedure are described in Ref. 2.

Table 1. Mathematical closure.

\begin{tabular}{ll}
\hline \multicolumn{1}{c}{ Unknown Variables } & \multicolumn{1}{c}{ Available Equations to Solve } \\
\hline Pressure & Mass conservation equation \\
Flow rate & Momentum conservation equation \\
Fluid temperature & Energy conservation equation of fluid \\
Solid temperature & Energy conservation equation of solid \\
Fluid mass (unsteady flow) & Thermodynamic equation of state \\
\hline
\end{tabular}

Figure 2 describes the three major parts of the GFSSP structure. The first part is the Graphical User Interface called VTASC (Visual Thermofluid Analyzer of Systems and Components). VTASC allows users to create a flow circuit by a point-and-click paradigm, and creates the GFSSP input file after the completion of the model building process. It can also create a customized GFSSP executable by compiling and linking User Subroutines with the Solver Module of the code. Users can run GFSSP from VTASC and postprocess the results in the same environment. The second major part of the program is the Solver and Property Module. This is the heart of the program that reads the input data file and generates the required conservation equations for all internal nodes and 


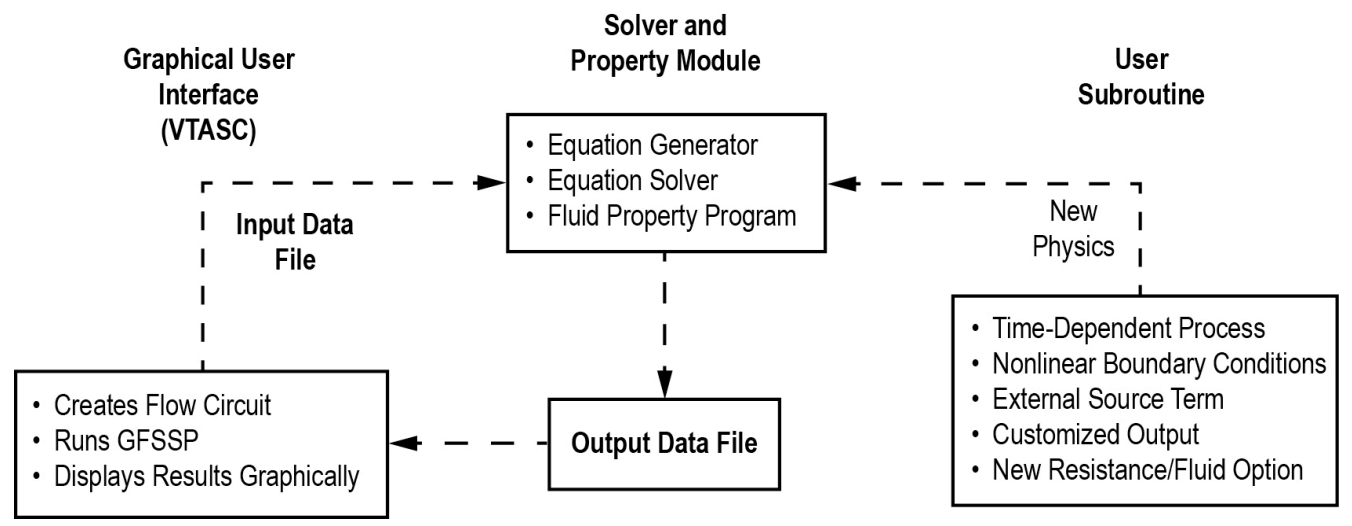

Figure 2. GFSSP's structure showing the interaction of three major modules.

branches with the help of thermodynamic property data. It also interfaces with User Subroutines to receive any specific inputs from users. Finally, it creates output files for VTASC to read and display results. The User Subroutine is the third major part of the program, consisting of several blank subroutines that are called by the Solver Module. These subroutines allow the users to incorporate any new physical model, resistance option, fluid, etc. in the model.

\section{A. Solution Steps}

Numerical modeling consists of the following 10 steps:

1) Subdivide the flow domain into fluid nodes and branches.

2) Subdivide the solid domain into solid nodes and conductors.

3) Connect the solid and fluid nodes with solid to fluid conductors.

4) At each fluid node, solve mass and energy conservation equations to calculate pressure and enthalpy of fluid and equation of state to compute resident mass of fluid.

5) At each fluid branch, solve the momentum conservation equations to calculate flow rate.

6) From pressure and enthalpy, calculate fluid temperature and all other thermodynamic and thermophysical properties required in governing equations.

7) At each solid node, solve the energy conservation equation to calculate temperature of the solid node. Subdivide the flow domain into fluid nodes and branches.

8) Steps 4) through 7) are repeated until convergence.

9) Steps 4) through 8) are repeated for each time step.

10) Terminate the calculation when final time step is reached.

Figure 3 shows the schematic of the mathematical closure and interrelation of the variables.

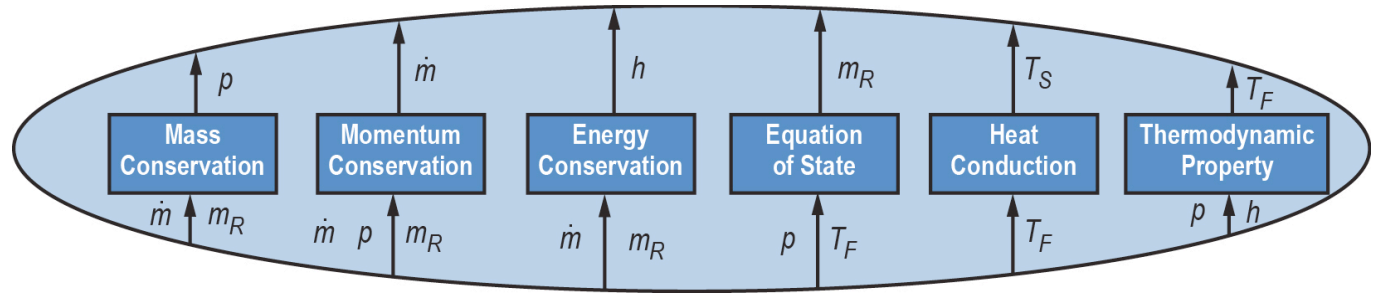

Figure 3. Schematic showing the mathematical closure and interrelation of the variables.

\section{Test Program}

The propellant tank used for the test program is a flight-like tank with a capacity of approximately $600 \mathrm{ft}^{3}$ (4500 gal). The barrel has a diameter of $10 \mathrm{ft}$ and is capped with elliptical domes giving an overall length of $10 \mathrm{ft}$. The tank walls are very thin stainless steel; the total mass is approximately $300 \mathrm{lb}$. The tank is insulated with two layers of fiberglass batts and an outer covering of Reflectix ${ }^{\circledR}$ double-reflective insulation. The tank support ring 
rests on a $3 / 4$-inch-thick ring of G-10 fiberglass epoxy laminate. To prevent condensation, the tank is shrouded with a plastic bag that is purged with dry nitrogen (for $\mathrm{LN}_{2}$ tests) or helium (for $\mathrm{LH}_{2}$ tests).

The tank rests on load cells to measure the mass of the tank and its contents. Liquid and vapor temperatures inside the tank are measured by a silicon diode rake with stations at 10 fill levels. Additional silicon diodes are placed on the inside and outside of the tank wall at the same levels. Two pressure transducers measure ullage pressure. Flowmeters provide the mass flow rates of facility-provided pressurant entering the tank and ullage gas venting from the tank.

The phase A test program concentrated on understanding the thermodynamic behavior of the tank and its contents. At different fill levels of $\mathrm{LN}_{2}$ and $\mathrm{LH}_{2}$, the tank was allowed to reach a quasi-steady state in which the vent flow rate was approximately constant. The total heat load on the tank was estimated based on the rate of change in mass multiplied by the heat of vaporization of the cryogenic propellant. When approximately $90 \%$ full of $\mathrm{LN}_{2}$, the estimated heat load into the tank was 4900 to $5300 \mathrm{~W}$. The temperature rake also provided information on ullage temperature stratification.

Phase A testing also included pressurization tests. When filled with $\mathrm{LN}_{2}$, the tank could be pressurized through a flight-like diffuser with facility-provided nitrogen or helium. This allows pressurization performance of an autogenous IVF system to be compared to a conventional pressurization by onboard helium tanks.

The phase B test program explores ullage gas mixing and tank pressurization through an IVF loop. The loop is added to supplement the facility pressurant system. The IVF loop directs vented ullage gas to a blower motor and heat exchanger and then returns the warm gas to be reinjected into the ullage. The flight-like diffuser is replaced with an injector that provides pressurant at high inlet velocities designed to encourage ullage mixing. Mixing of the ullage gas is desirable so that the vented vapor is much cooler than the reinjected gas, preventing rapid heating of the ullage and improving the performance of the heat exchanger. The blower motor substitutes for the compressor that will be delivered for phase $\mathrm{C}$ testing.

\section{GFSSP Models of Integrated Vehicle Fluid Test System}

As mentioned in the previous section, a flight tank has been used for testing the IVF system. The intent was to develop an integrated model of the tank and IVF loop consisting of the blower/compressor and heat exchanger. Separate models were developed, tested, and verified with test data and later integrated to develop a system-level model.

\section{A. Tank Model}

In the past, GFSSP has been used to model tank pressurization. ${ }^{3,4}$ The early models used a single node ullage and a single node liquid propellant with a heat transfer between ullage to tank wall and ullage to liquid propellant. In recent years, ${ }^{5}$ multiple ullage nodes have been used to model self-pressurization in an $\mathrm{LH}_{2}$ tank. The multiple nodes were used to model tank stratification in order to more accurately model the heat transfer between ullage to wall. Natural convection correlations ${ }^{6}$ have been used in these models to compute heat transfer between ullage to wall and ullage to liquid. In this study, multiple nodes represented a one-dimensional network; there has been no attempt to model recirculation. In the present IVF tank model, multiple nodes were arranged to simulate an axisymmetric geometry capable of modeling a recirculating flow pattern typically observed in a stratified environment.

The geometric transformation of the flight tank to a computational model is shown in Fig. 4. The tank has been conceived to consist of a core and a boundary layer to enable recirculation due to stratification. The core and boundary layer have been modeled as two cylinders with different diameters.

The GFSSP model of the tank is shown in Fig. 5. The tank ullage is represented by 10 nodes $(2,8,9,10,11,23$, 24, 25, 26, and 27). Nodes 23 through 27 represent the core and the remaining nodes represent the boundary layer. Node 4 represents liquid and node 1 is the pseudoboundary node that represents liquid-vapor interface. There are 24 solid nodes representing metal and insulation. The outer surface of the insulation is connected to the ambient through a solid to ambient conductor to allow convective heat transfer to the tank. The vent line (branch 231) is connected to ambient. The drain line (45) is closed during modeling of boiloff and pressurization. 


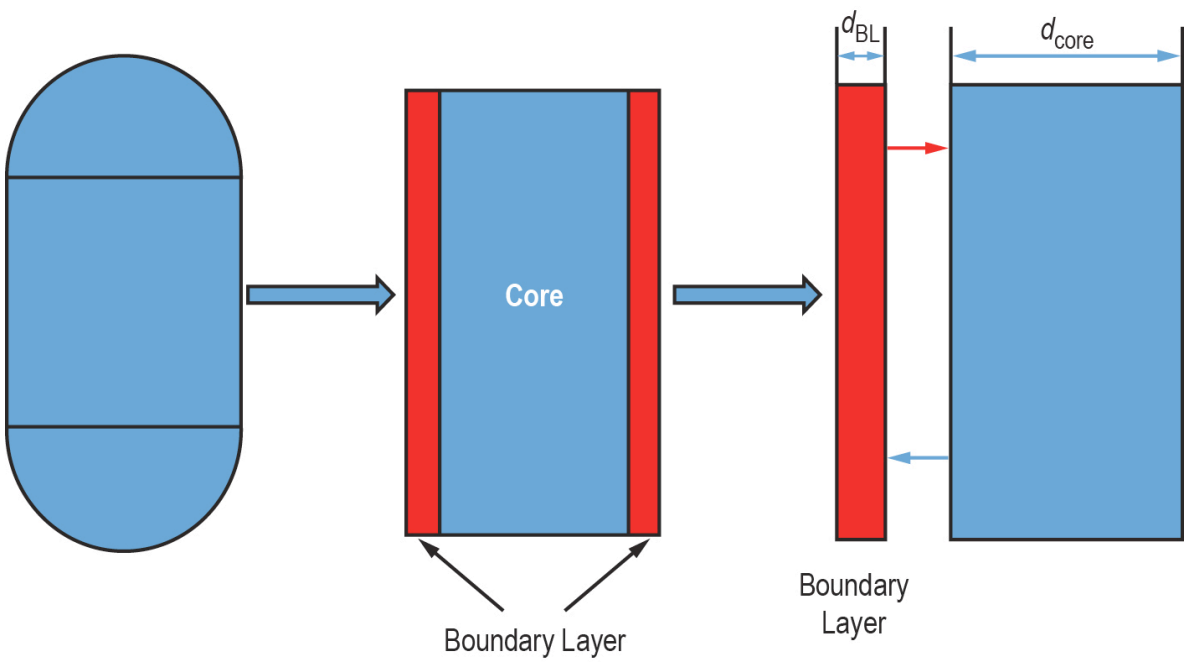

Figure 4. Geometric transformation of tank to computational model.

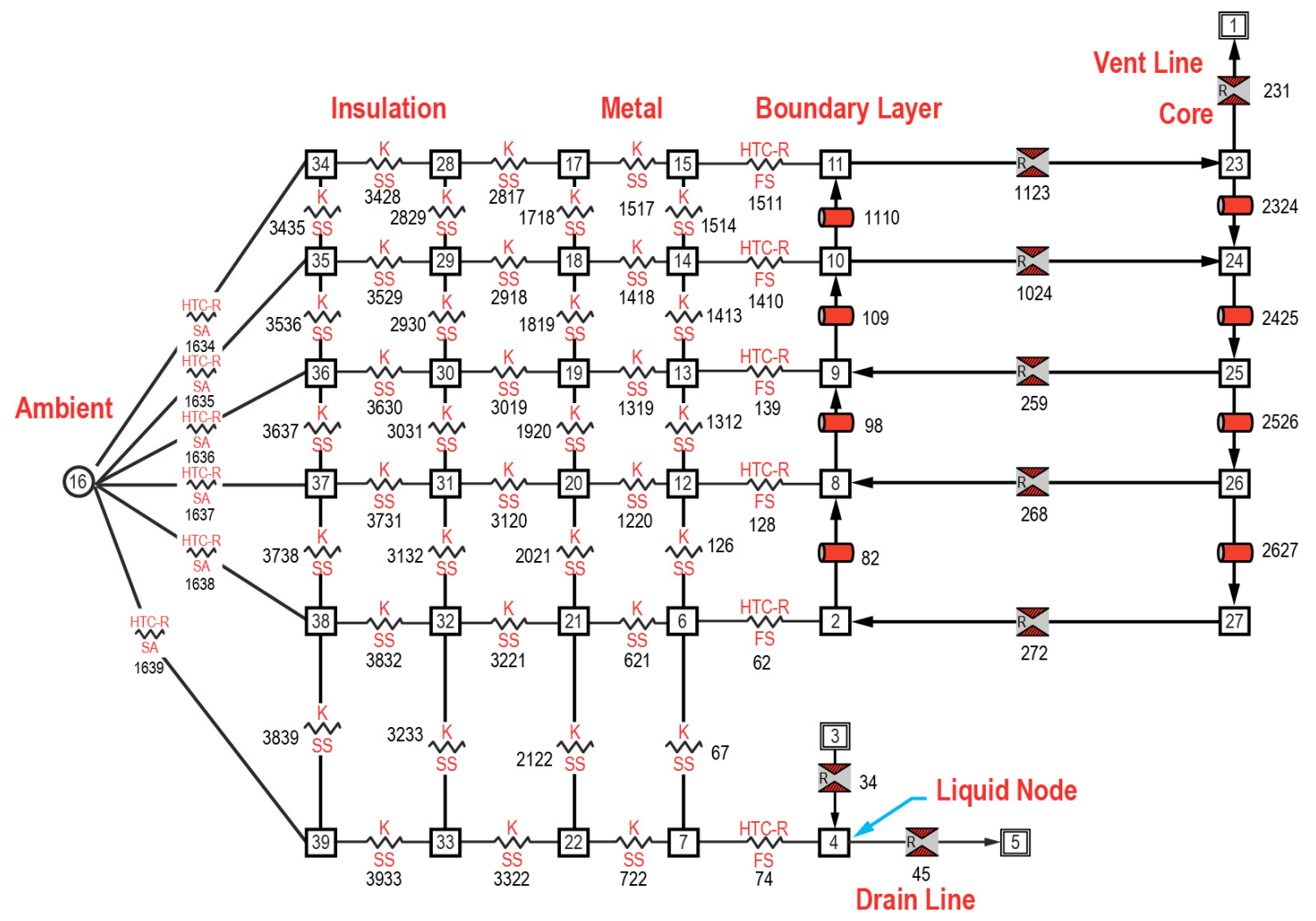

Figure 5. GFFSP model of the tank.

\section{B. Integrated Vehicle Fluid Loop Model}

The IVF loop model is shown in Fig. 6. This model represents the facility flow circuit driven by a blower that circulates the ullage gas from the tank through the heat exchanger and returns it to the tank for pressurization. This network flow model contains a vent line, all bends and valves, blower, heat exchanger, and return press line. This model was developed as a steady-state model with two boundary nodes set at the ullage pressure. The blower was modeled as a pump with a given horsepower and efficiency. 


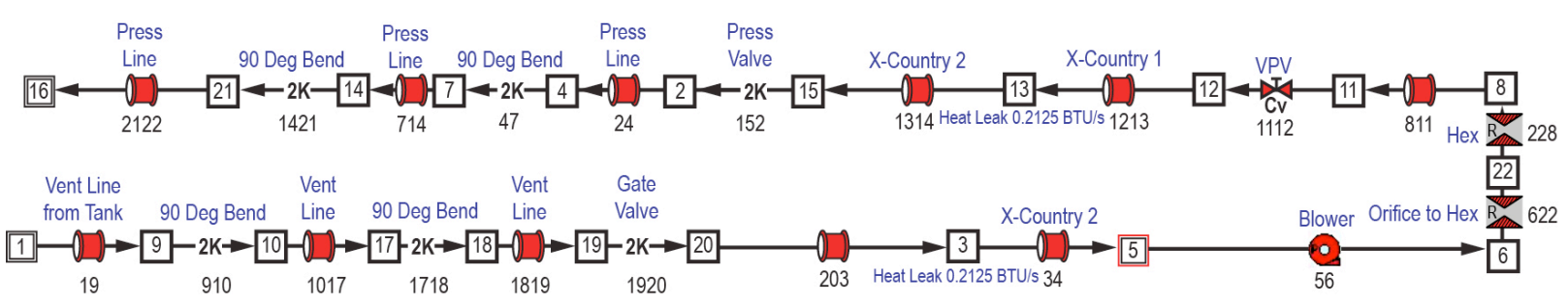

Figure 6. GFFSP model of IVF loop.

\section{Heat Exchanger Model}

The GFSSP model for the gaseous nitrogen $\left(\mathrm{GN}_{2}\right)$-Kryotox heat exchanger is shown in Fig. 7. A counterflow heat exchanger has been used to extract heat from the Kryotox, which is a coolant for the ICE. $\mathrm{GN}_{2}$ is heated by Kryotox.

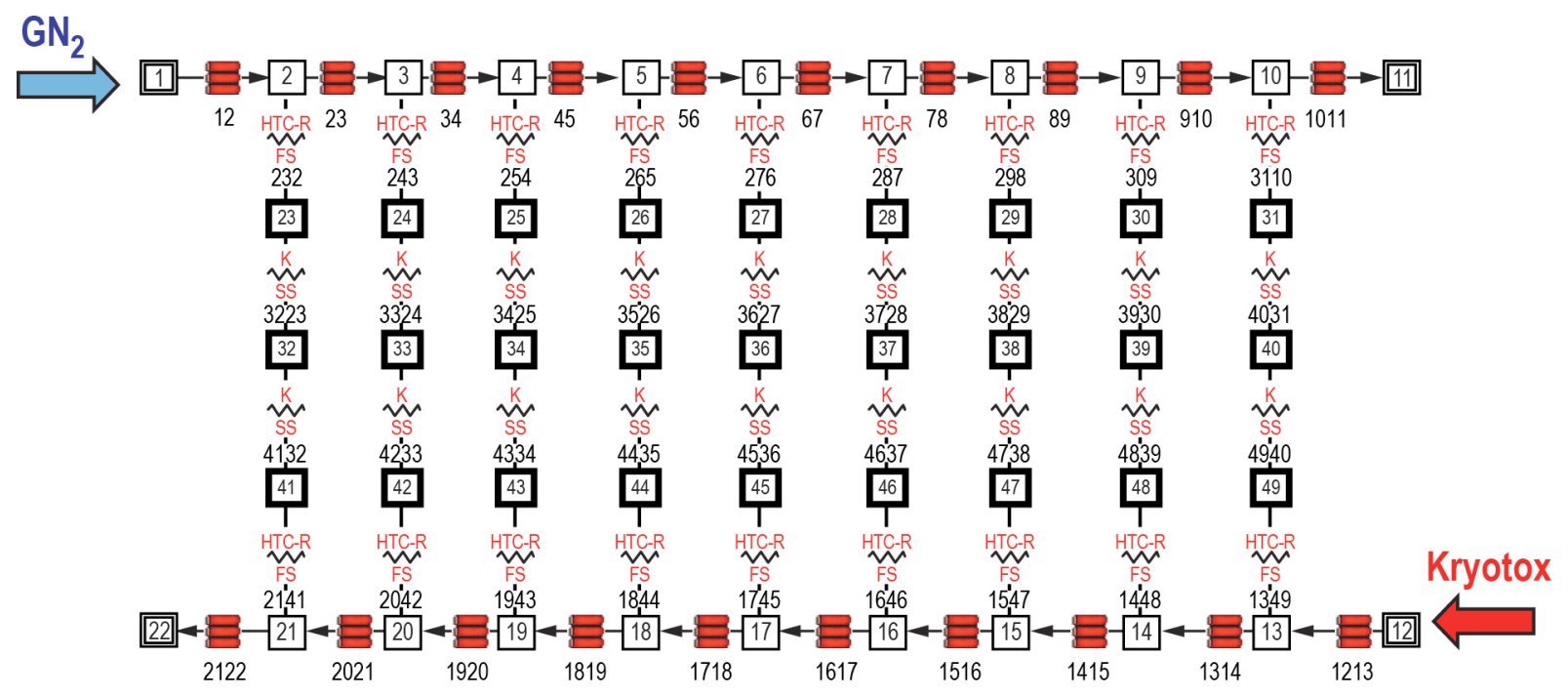

Figure 7. GFSSP model of $\mathrm{GN}_{2}$-Kryotox heat exchanger.

\section{Integrated Model}

An integrated model of the tank pressurization system and heat exchanger has been developed. As a first step, the tank model and the IVF loop model was integrated into the tank pressurization model as shown in Fig. 8. Instead of integrating tank pressurization and heat exchanger models, an alternate approach was adopted. In this approach, the tank pressurization and heat exchanger models were run separately, but during the run, the model exchanged data to provide boundary conditions for each other. This is an example of nonlinear boundary conditions that change with iterations. Therefore, a numerical algorithm must be in place to ensure boundary conditions are converged before the solution proceeds to the next time step. The schematic of the integrated model of the tank pressurization and heat exchanger is shown in Fig. 9. The algorithm steps are as follows:

- Tank pressurization model:

1) In the first iteration, guess equivalent resistance (AKEFF) and enthalpy at node 108.

2) Run tank pressurization model to a converged solution with guessed values and write $\mathrm{p}_{107}, \mathrm{~T}_{107}$, and $\mathrm{p}_{108}$ in a data file.

3) Run heat exchanger model from the User Subroutine of the tank pressurization model.

- Heat exchanger model:

4) Read $p_{107}, T_{107}$, and $p_{108}$ from data file created by tank pressurization model.

5) Run the model until convergence.

6) Calculate equivalent resistance, AKEFF.

7) Write AKEFF and $h_{6}$ in a data file. 
- Tank pressurization model:

8) Read AKEFF and $h_{10}$ from the data file generated by the heat exchanger model and set $h_{108}=h_{10}$.

9) Check convergence of AKEFF and $\mathrm{h}_{108}$ and repeat steps 2) through 8) until convergence.

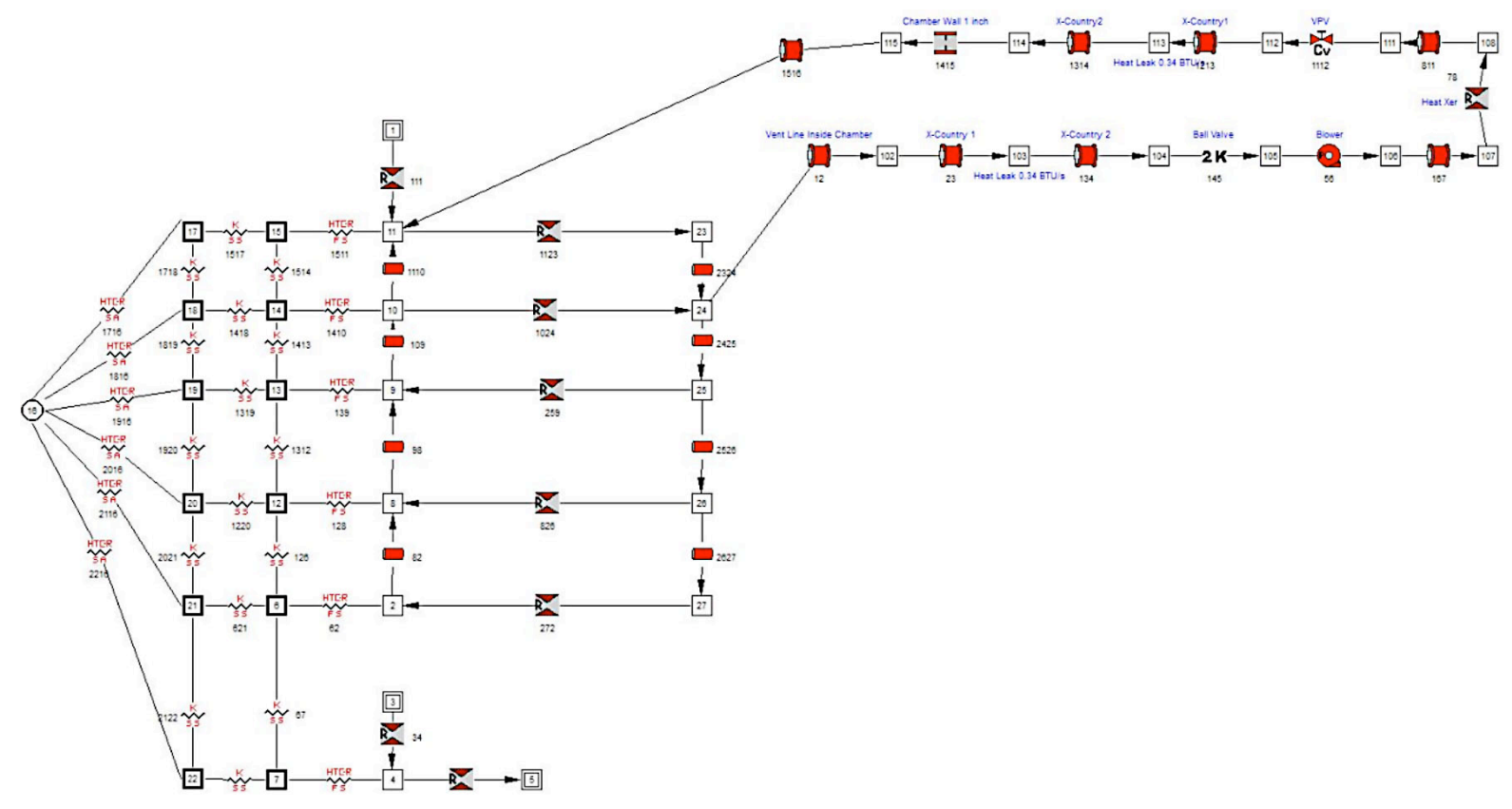

Figure 8. Tank pressurization model consisting of tank and IVF loop.

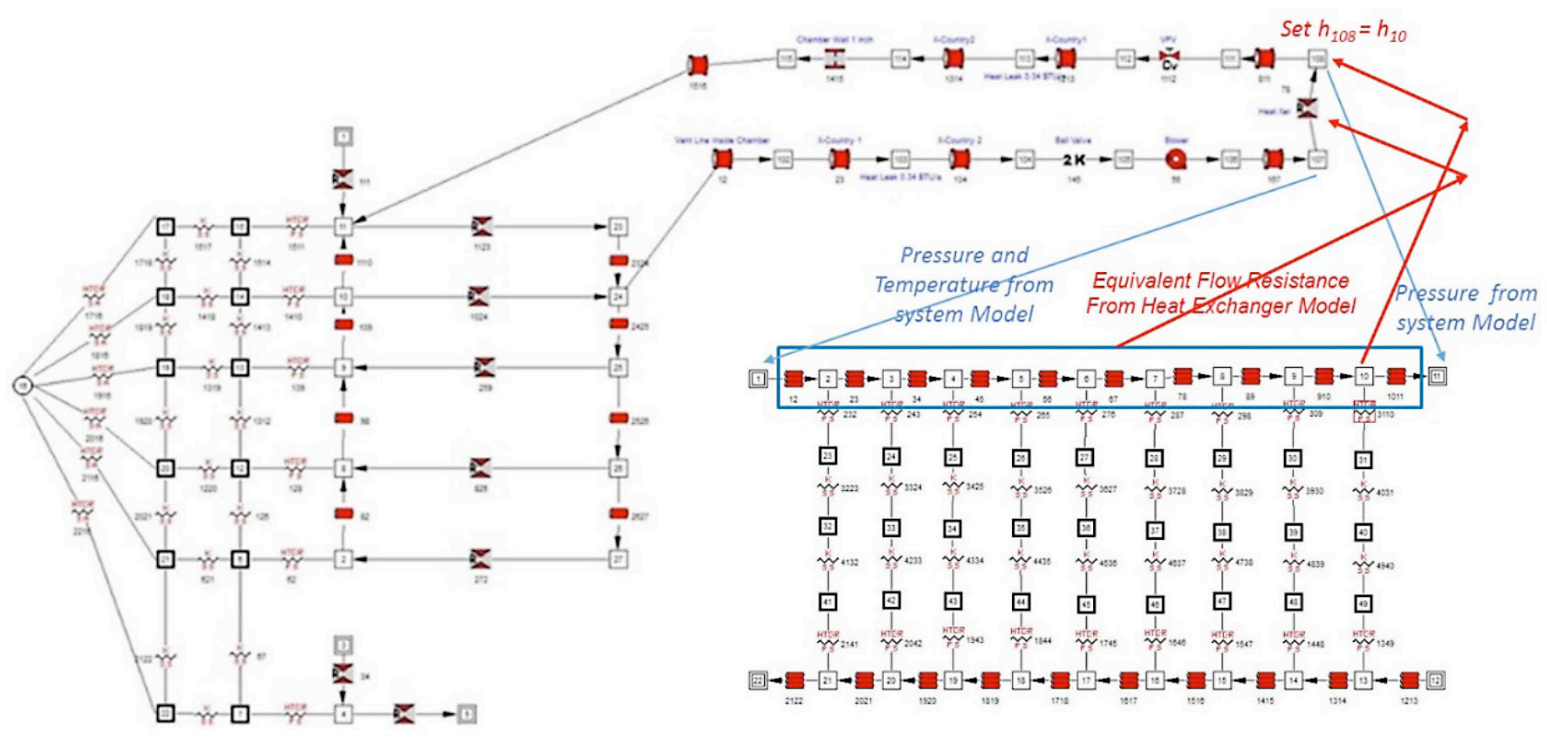

Figure 9. Integrated model of tank, IVF test loop, and heat exchanger. 


\section{Results and Discussion}

Results and discussions are covered in three subsections. Section A describes the verification of numerical predictions of boiloff data with test results. The comparison of the numerical prediction of the tank pressurization with test data has been discussed in section B. Section C describes the results of the integrated model.

\section{A. Boiloff Model}

The GFSSP boiloff model, as depicted in Fig. 10, consisted of the tank and the vent system. During boiloff, the generated vapor leaves the tank through a vent system. The vent system starts from the tank and ends in the atmosphere. The model contains the following assumptions:

1) The liquid within the tank is represented by node 4 corresponding to a tank fill level of $40 \%$.

2) The ullage within the tank is described by nodes 2 and 8-11 representing the ullage boundary layer and nodes 23-27 representing the ullage core. Nodes 2 and 27, 8 and 26, 9 and 25, 10 and 24, and 11 and 23 correspond to tank fill levels of $40 \%, 50 \%, 69 \%, 86 \%$, and $97 \%$, respectively.

3) The tank wall is represented by solid nodes $6-7,12-15$, and $17-22$.

4) The vent system is represented by nodes $46-49$ and branches $2346,4647,4748,4849$, and 491.

5) The atmosphere, represented by node 1 , is at constant temperature and pressure of $70^{\circ} \mathrm{F}$ and 14.7 psia, respectively.

6) The ambient, represented by node 16 , is at a constant temperature of $70^{\circ} \mathrm{F}$.

7) Dimensions and thermal/fluid properties of the tank and vent system as well as the test conditions are incorporated into the model.

8) Conductive heat transfer along the wall is neglected.

9) Vent system is insulated, so heat transfer from the environment to each system is ignored.

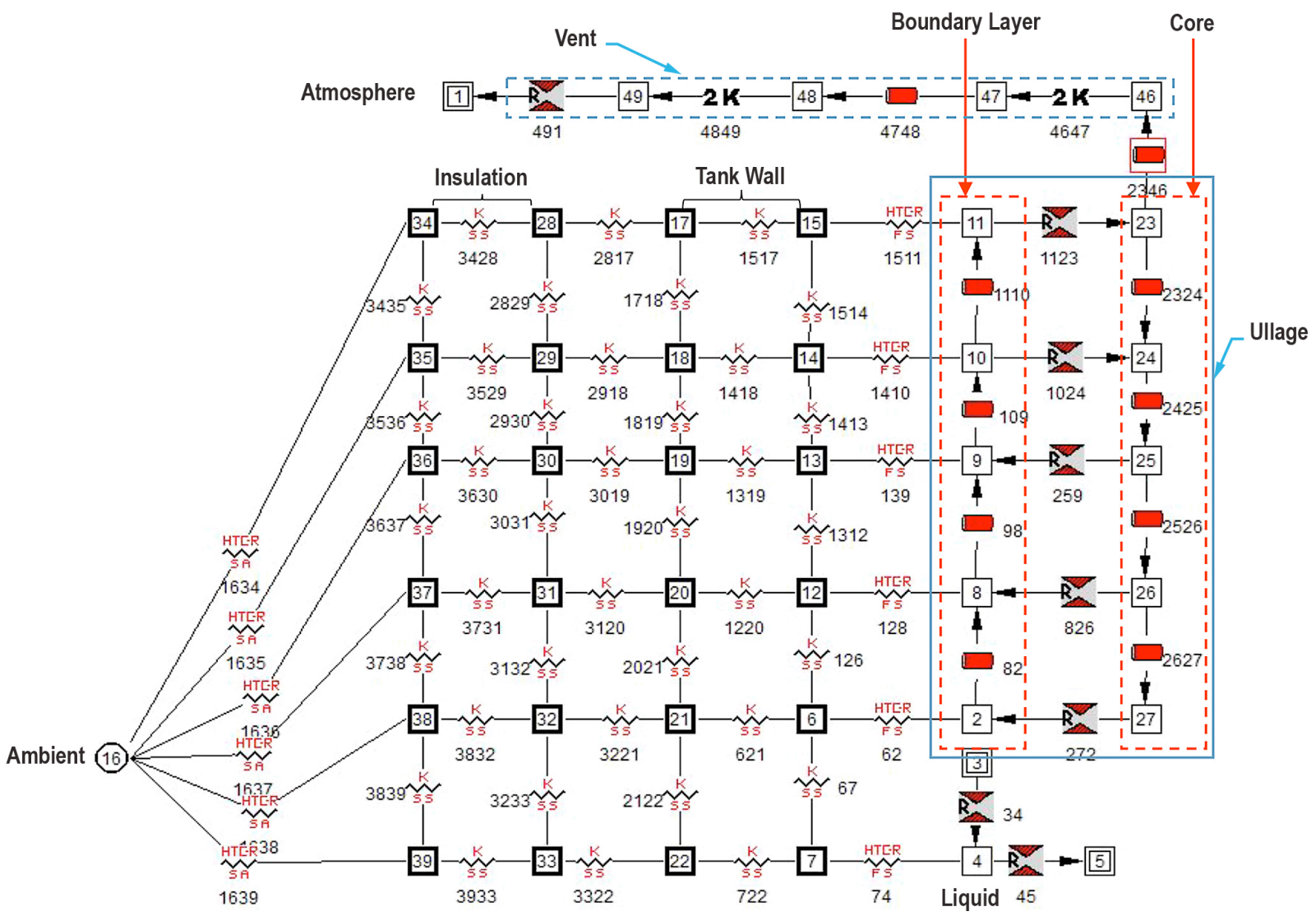

Figure 10. GFSSP model representation of boiloff process. 
The boiloff model was correlated by incorporating the boiloff test conditions at $40 \%$ tank fill level. A comparison between computed ullage pressures and their measured values are shown in Fig. 11. During the boiloff, the ullage pressure was kept at a constant value of $18.7 \mathrm{psia}$. Initially, the model underpredicted the ullage pressure slightly; however, after about $1000 \mathrm{~s}$, the computed ullage pressures and those of the test data were in good agreement.

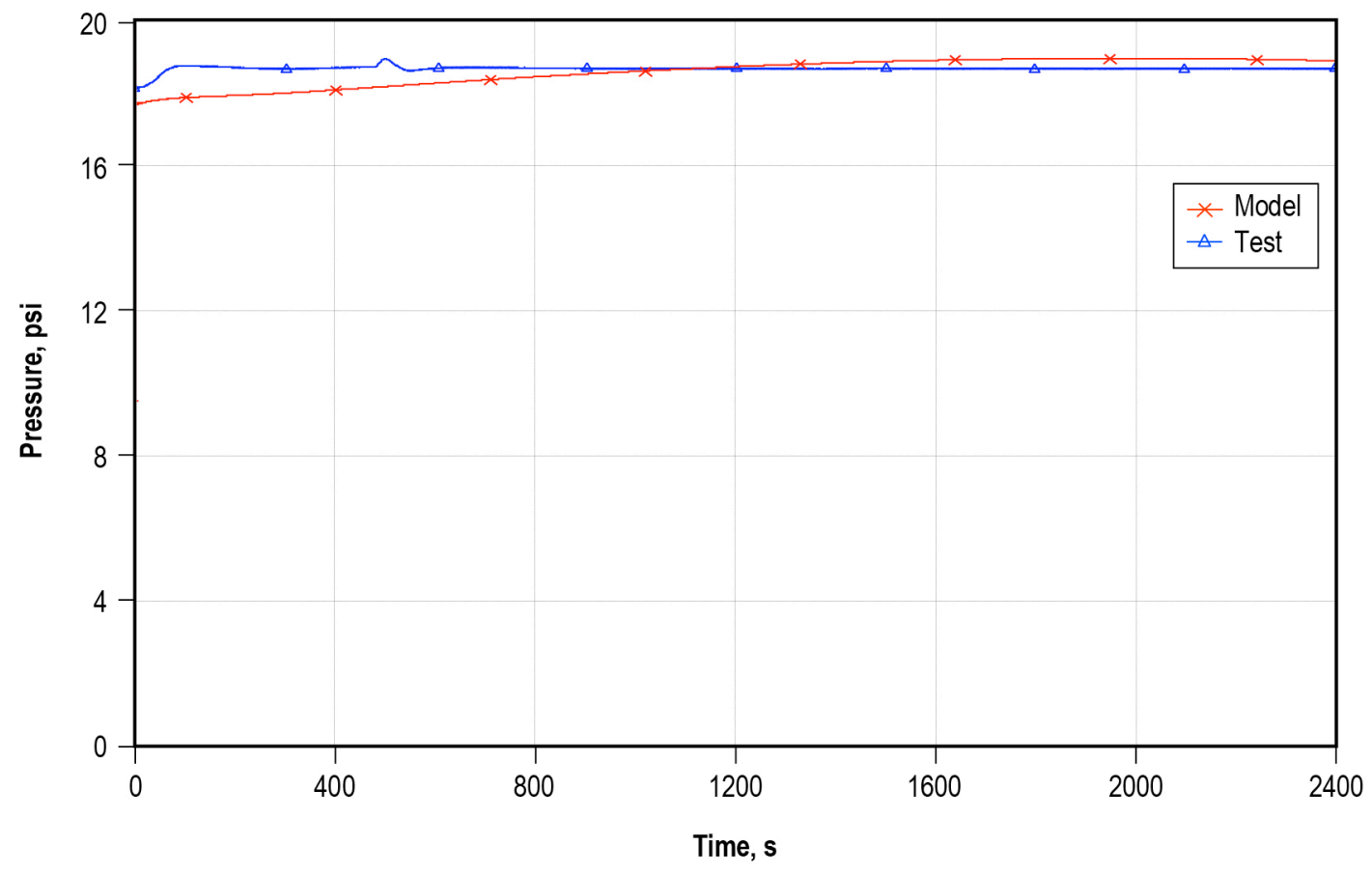

Figure 11. Tank ullage pressure history during boiloff.

Comparison between computed boiloff mass flow rates and measured values are presented in Fig. 12. The initial model predictions were lower than the test data; however, after around $1000 \mathrm{~s}$, the model predictions were in reasonable agreement with the measured values.

Computed heat leaks into the liquid and ullage, as well as the total heat leak into the tank, are shown in Fig. 13. The computed heat leaks into the liquid and ullage were about $1900 \mathrm{~W}(1.8 \mathrm{Btu} / \mathrm{s})$ and $2200 \mathrm{~W}(2.08 \mathrm{Btu} / \mathrm{s})$, respectively.

\section{B. Pressurization Model}

Figure 14 shows the GFSSP model of the phase A autogenous pressurization test. It is a minor modification of the tank model shown in Fig. 5. The boundary node at the upper right represents the facility nitrogen source. Warm nitrogen gas flows through the diffuser and into the ullage core. The temperature of the pressurant gas is based on measurements in the facility line just prior to entering the tank. GFSSP's flow regulator option is activated for the diffuser branch so that the inlet flow rate matches the flowmeter measurements. The measured mass flow rate is shown in Fig. 15. There is a 150 -s initial pressurization flow at $0.13 \mathrm{lb} / \mathrm{s}$, followed by five 7 -s bursts at $0.05 \mathrm{lb} / \mathrm{s}$ to maintain ullage pressure at $30 \mathrm{psig}(44.7 \mathrm{psia})$.

For the test case modeled here, the tank was filled with $\mathrm{LN}_{2}$ to $87.6 \%$ of the total volume, based on the load sensor measurements. The liquid level is approximately $2 \mathrm{ft}$ from the top of the tank. The five layers of ullage nodes correspond to the $90 \%, 95 \%, 98 \%, 99.5 \%$, and $100 \%$ fill levels. The initial ullage temperatures are set by the rake measurements at the $90 \%, 95 \%$, and $98 \%$ levels. The initial wall temperatures are also set by the diode measurements at $90 \%, 95 \%$, and $98 \%$. Initial temperatures at the $99.5 \%$ and $100 \%$ levels, where measurements are not available, are assumed to be equal to the $98 \%$ level. The initial ullage pressure of $20.1 \mathrm{psia}$ is based on the average of the two ullage pressure transducers.

The tank vent is normally closed during pressurization. However, at the end of the first pressure cycle, the vent's relief function caused it to open for a period of $10 \mathrm{~s}$. This event is modeled with GFSSP's valve open/close option. 


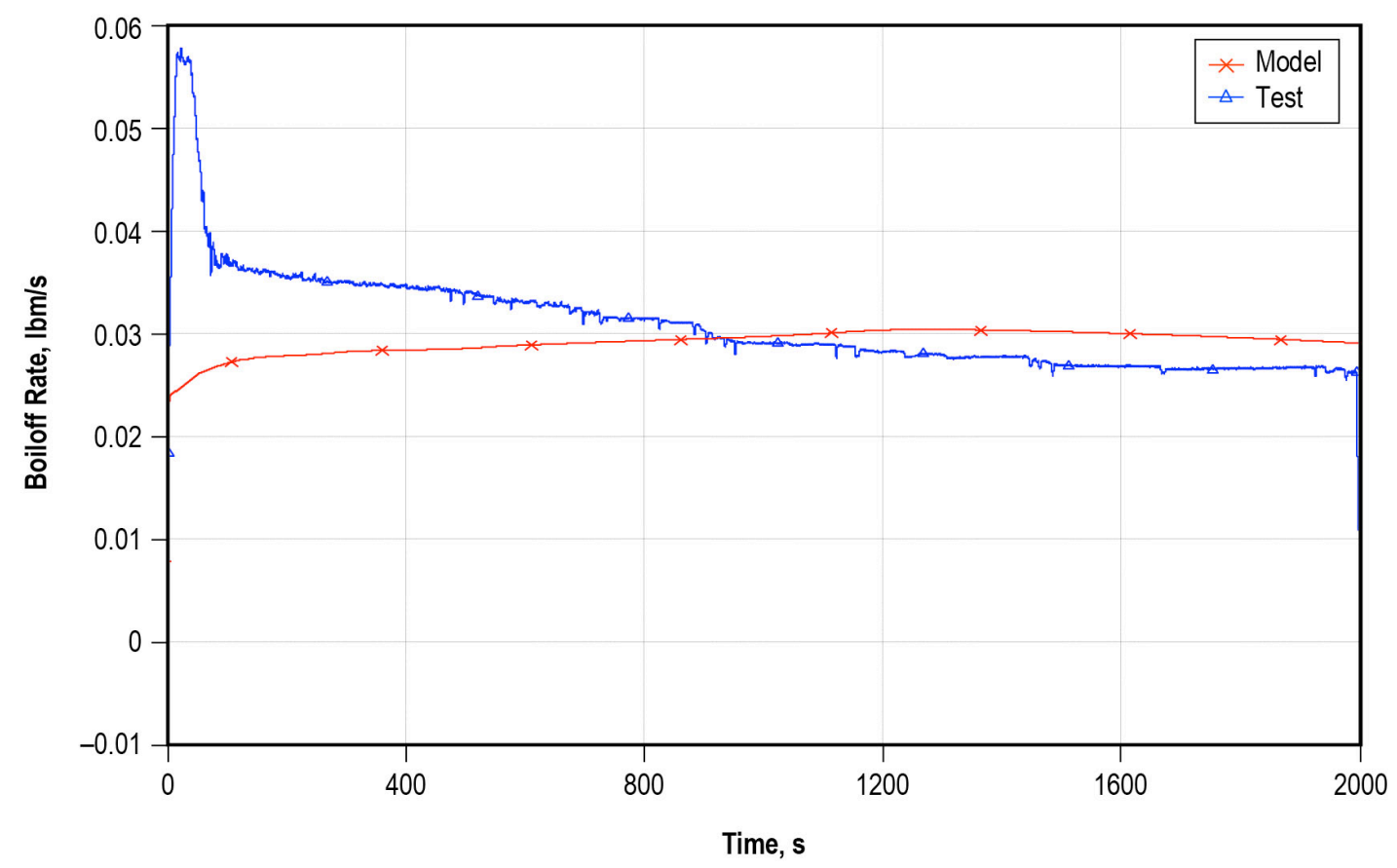

Figure 12. Boiloff rate history.

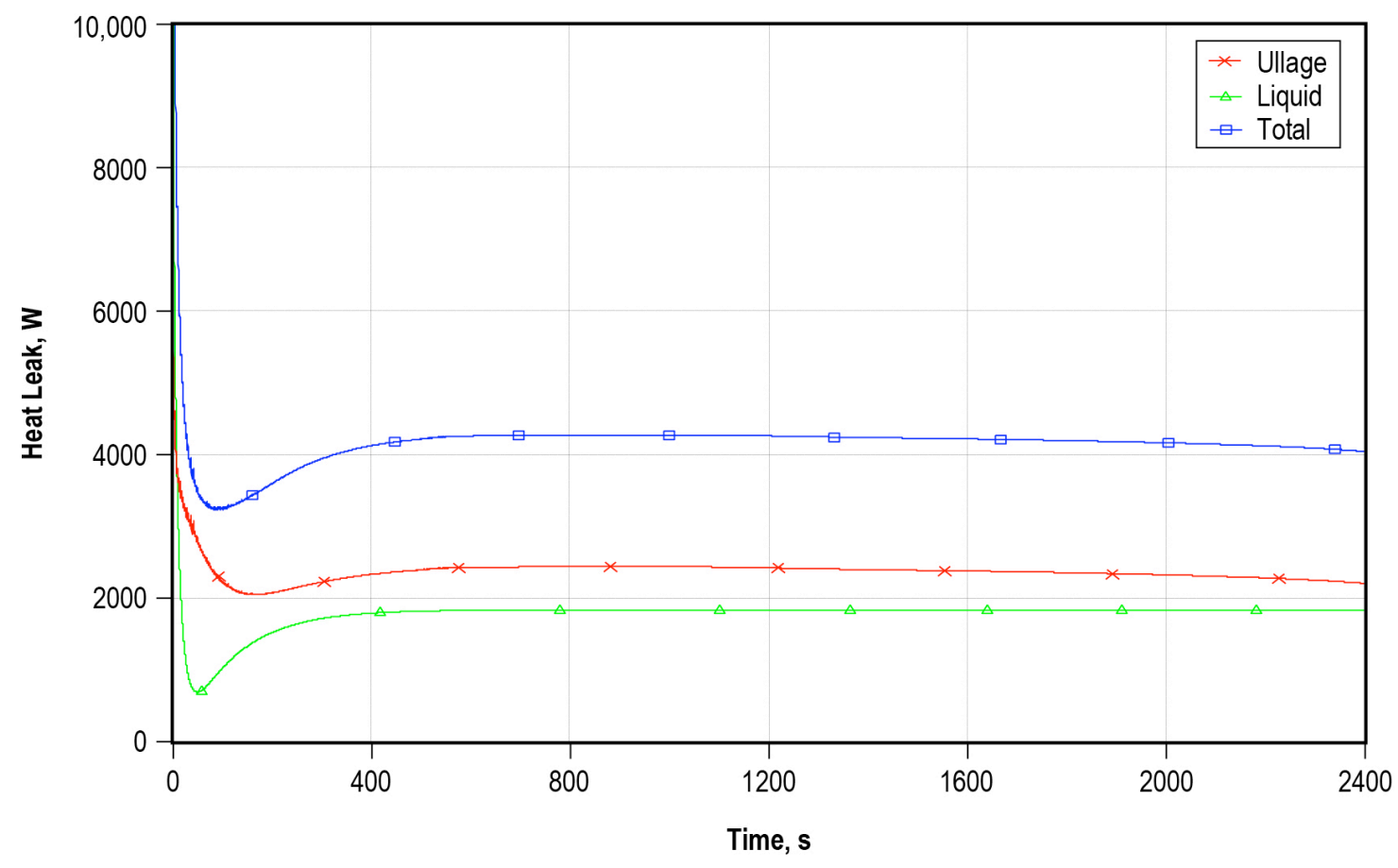

Figure 13. Computer heat leak histories.

The ambient temperature on the day of the test was $33^{\circ} \mathrm{F}$; this is fixed in the ambient node at the far left of Fig. 14. The solid nodes represent conduction through the two layers of fiberglass batts and the thin stainless steel wall. The convection coefficient from the tank wall to the boundary layer ullage gas and from the lowest level of the ullage gas to the cold propellant surface is calculated from natural convection correlations. 


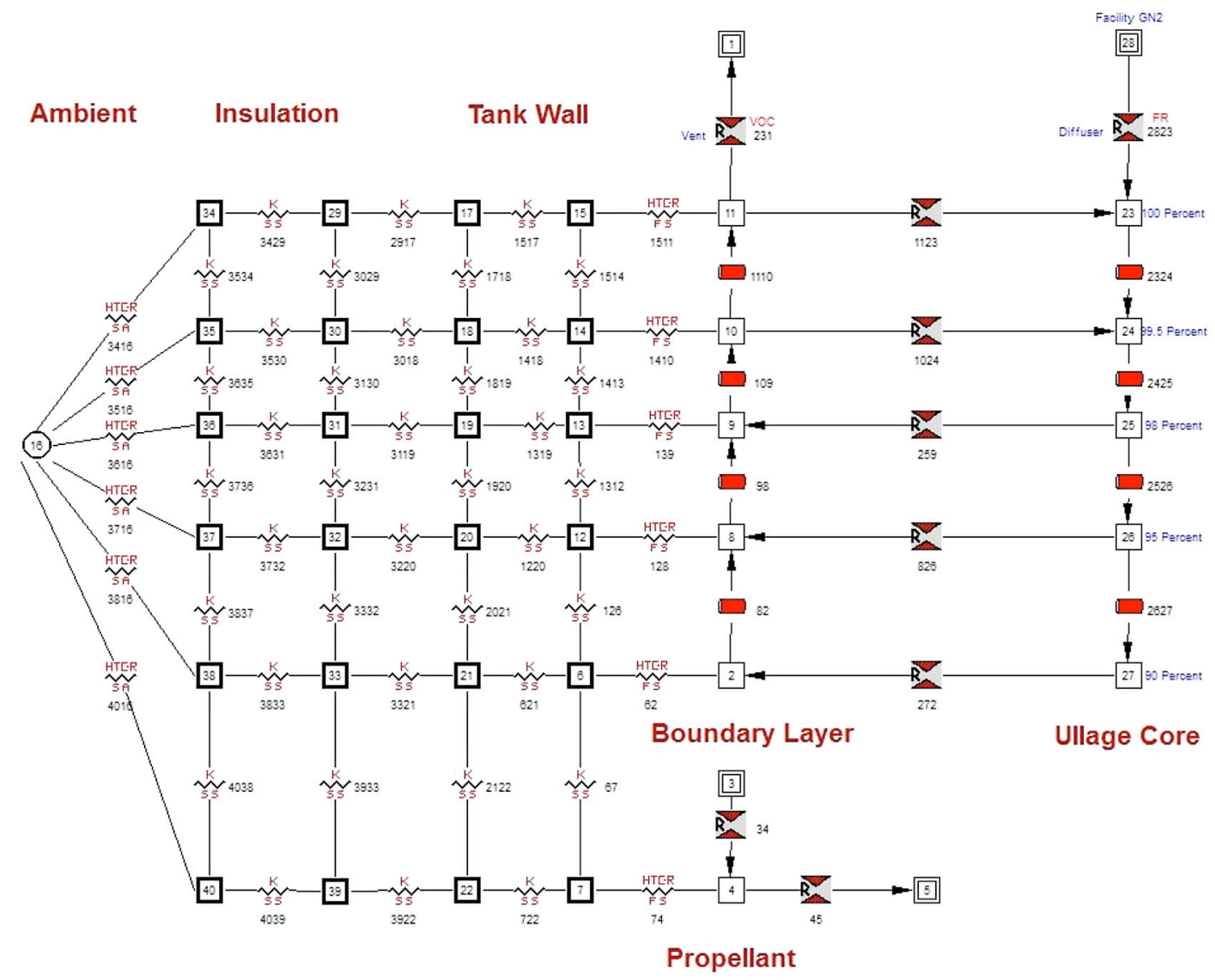

Figure 14. GFSSP model of phase A pressurization test.

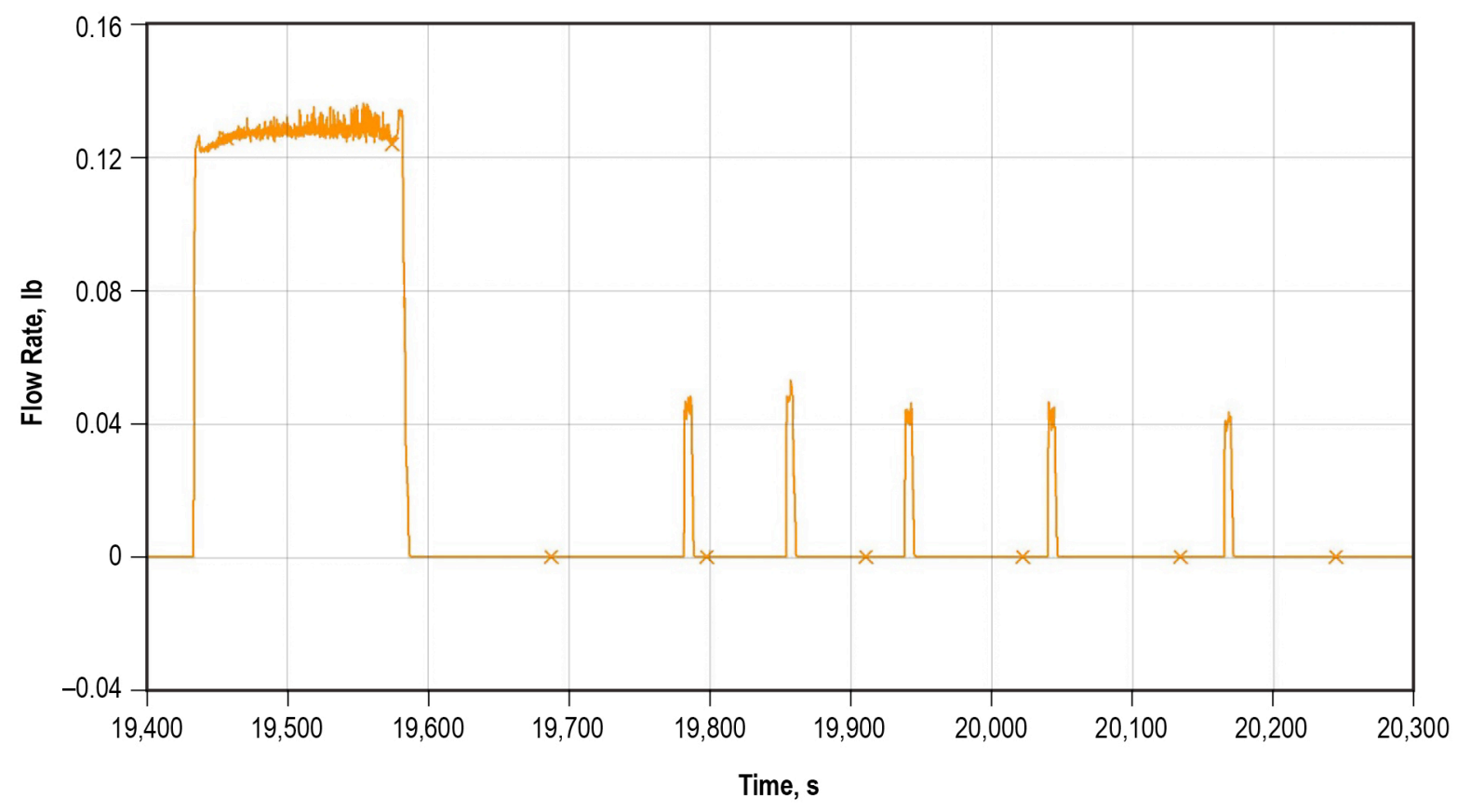

Figure 15. Measured pressurant flow rate.

11

American Institute of Aeronautics and Astronautics 
Figure 16 shows the measured ullage pressure compared to GFSSP's calculated ullage pressure. GFSSP overpredicts the pressure rise rate, resulting in a maximum pressure that is $7 \mathrm{psi}$ higher than measured. The predicted pressure decay rate is not as great as seen in the actual experiment.

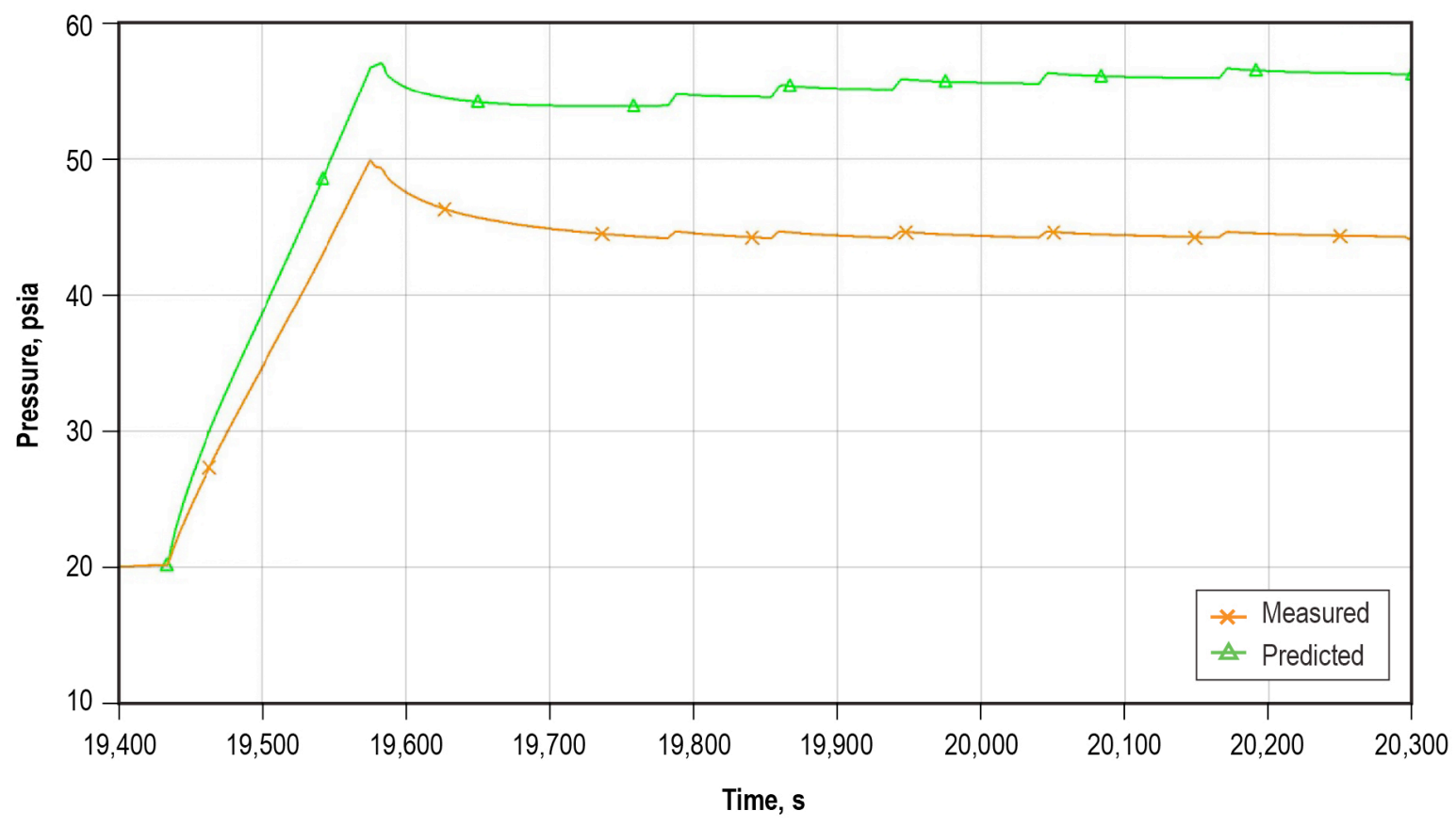

Figure 16. Measured and predicted ullage pressure.

Figures 17 and 18 show the measured and predicted temperatures at the $90 \%$ fill level for the ullage rake and tank wall, respectively. The model overpredicts the ullage temperature rise rate during initial pressurization, but afterwards, agreement is reasonable.

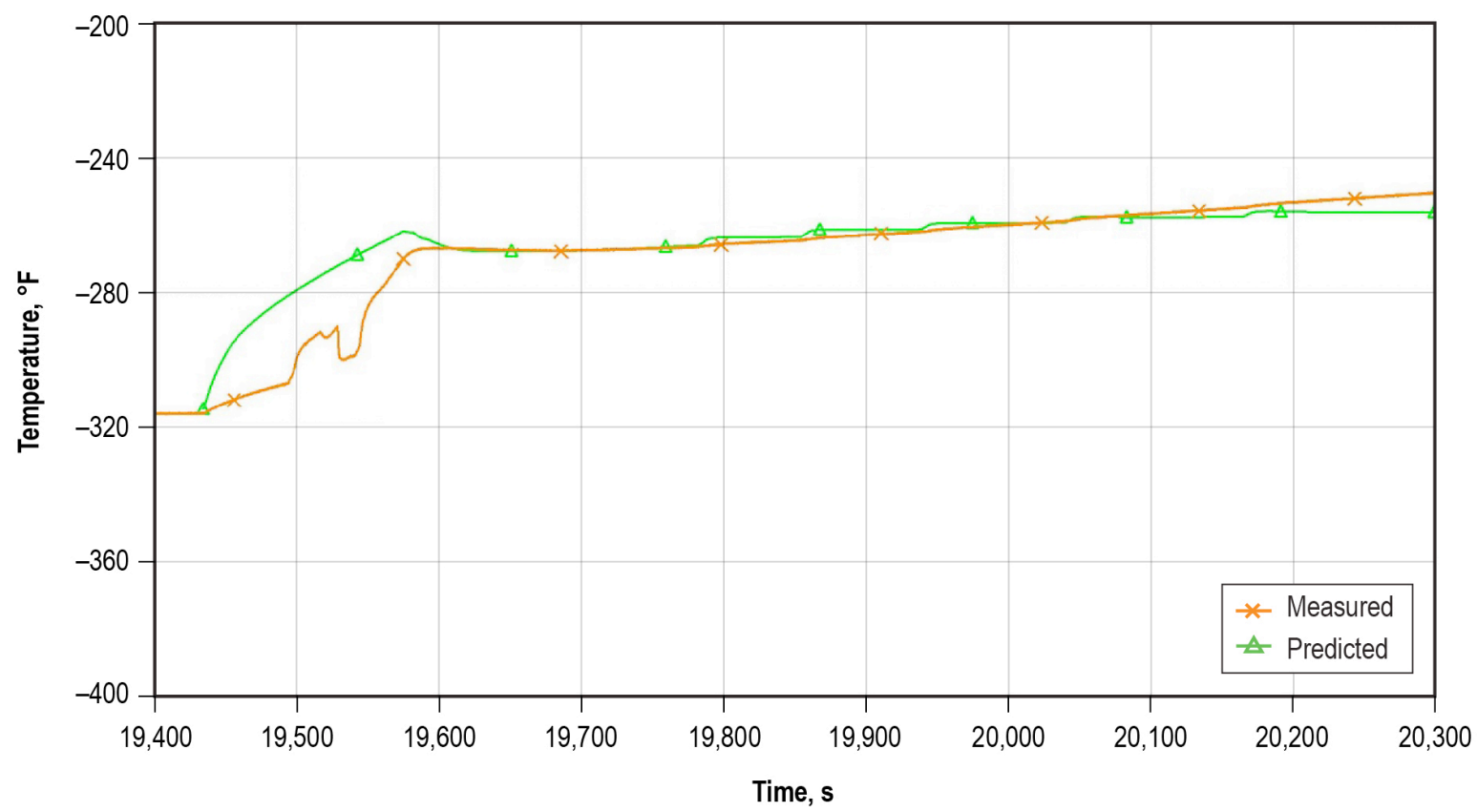

Figure 17. Measured and predicted ullage temperature at the $90 \%$ fill level. 


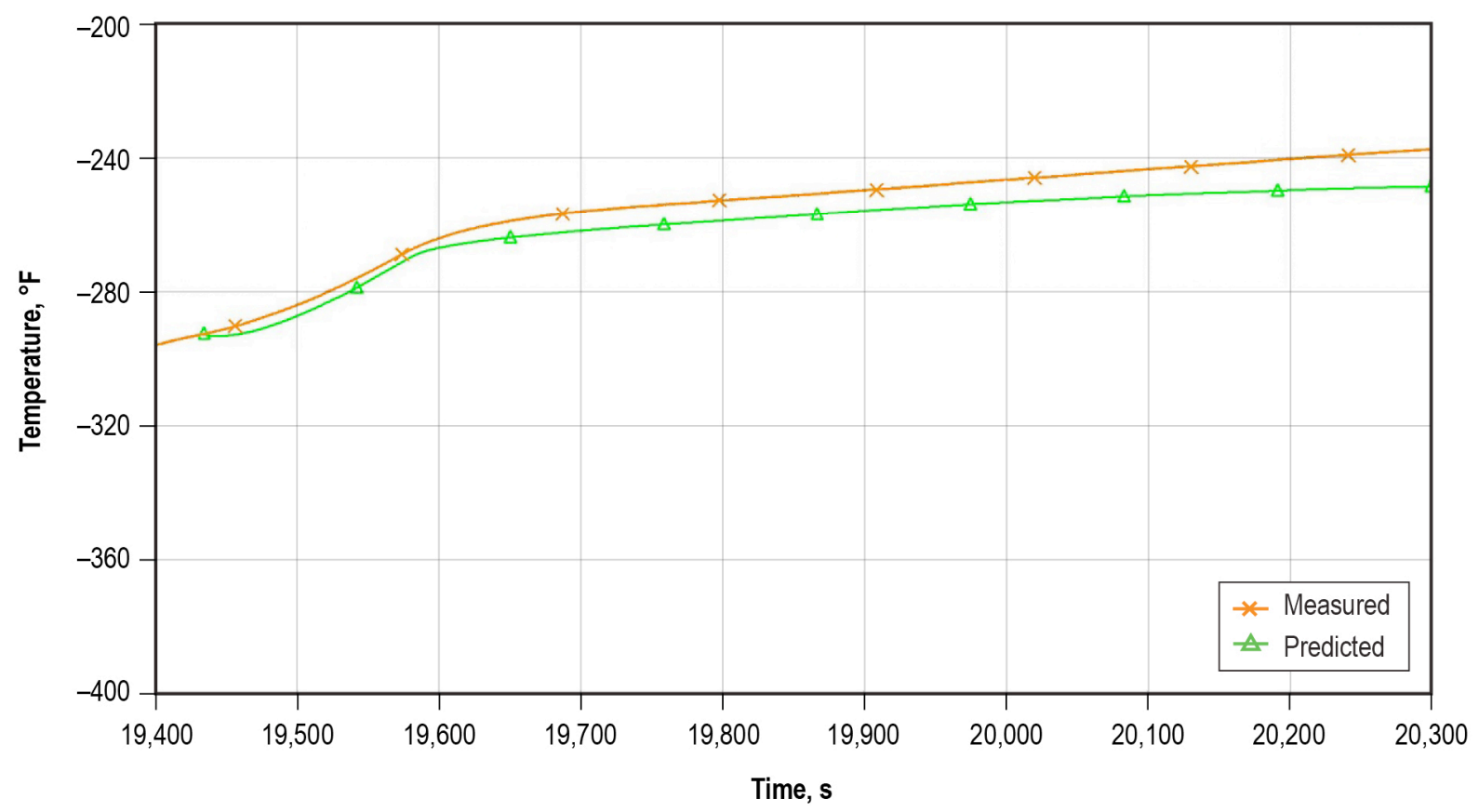

Figure 18. Measured and predicted tank wall temperature at the $90 \%$ fill level.

Figures 19 and 20 show the measured and predicted temperatures at the $98 \%$ fill level for the ullage rake and tank wall, respectively. In this case, the model has noticeably underpredicted the ullage and wall temperatures.

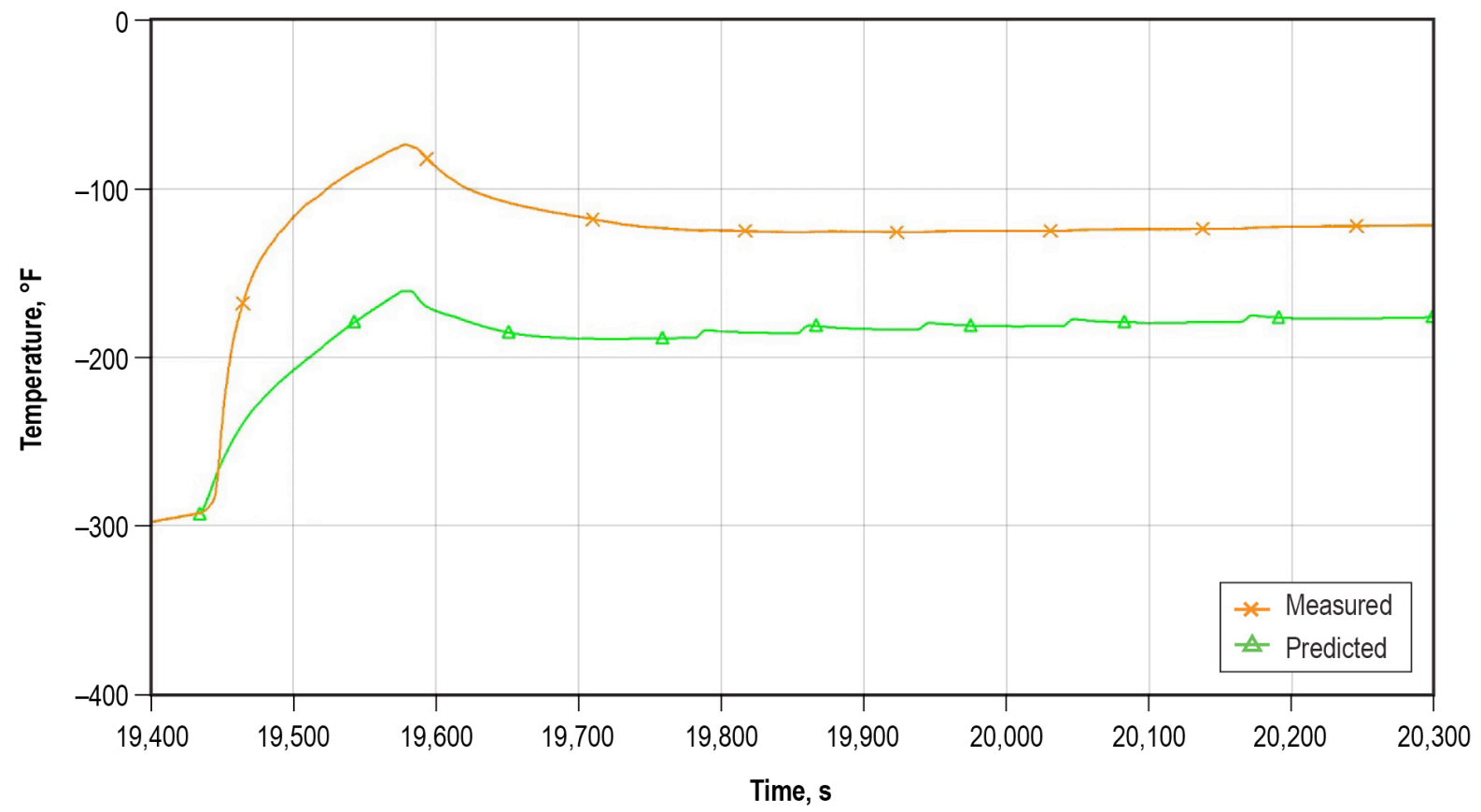

Figure 19. Measured and predicted ullage temperature at the $98 \%$ fill level.

There are several possible reasons for the discrepancy between the measured and predicted pressures and temperatures; the most likely involves heat transfer. The temperature of the incoming pressurant is based on measurements made in the facility line just upstream of the tank. The model does not account for heat transfer from

American Institute of Aeronautics and Astronautics 


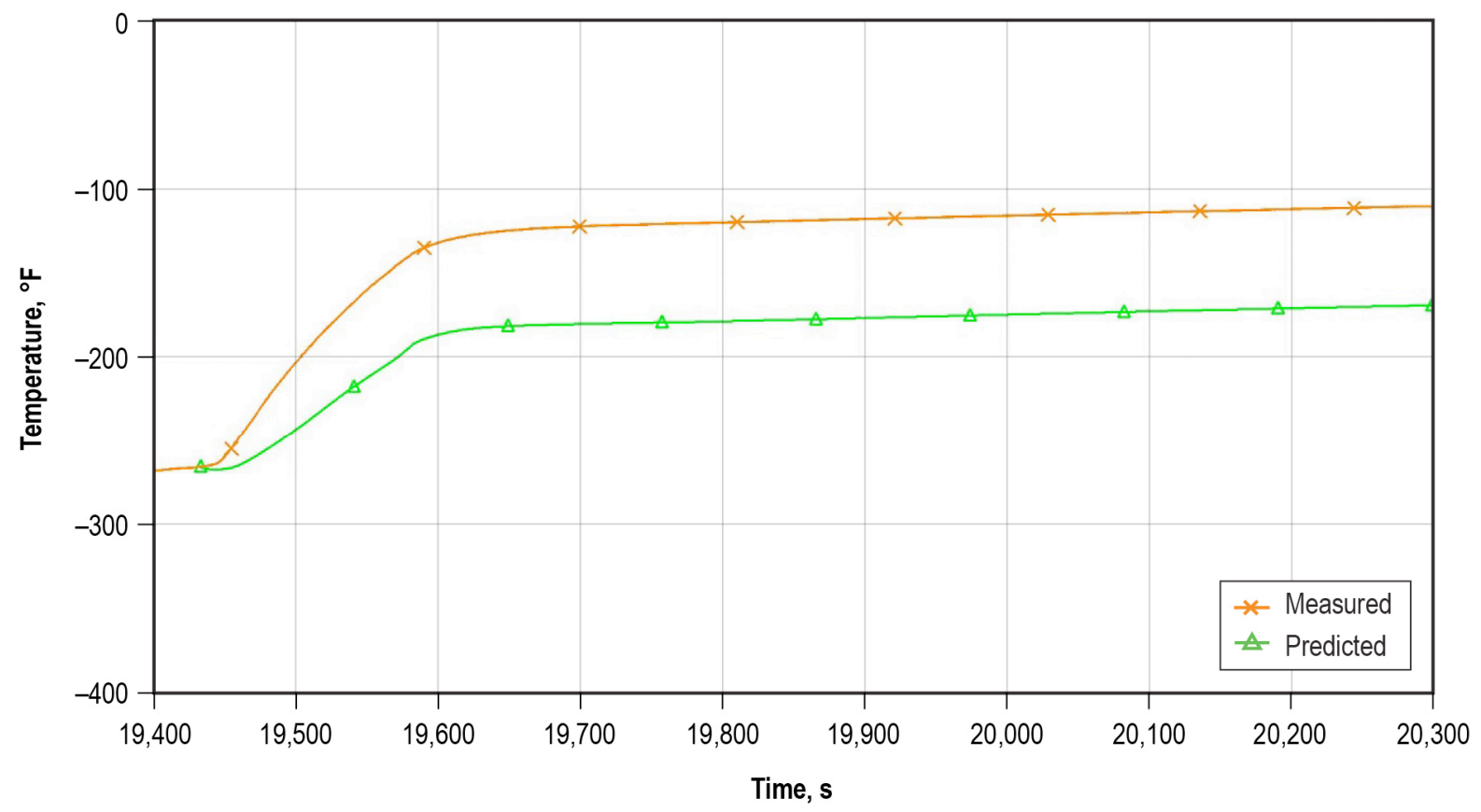

Figure 20. Measured and predicted tank wall temperature at the $98 \%$ fill level.

the pressurant to the cold diffuser as it enters the tank. The model has also not accounted for other sources of thermal mass which might not be negligible, such as the dome camera, ullage rake, and extra bulk of the manhole cover. In addition, there is great uncertainty in the heat transfer coefficient. Applying a multiplication factor of 4 to the heat transfer coefficient was found to reduce the maximum predicted ullage pressure by 8 psia. Another possible source of error is uncertainty in the pressurant gas flow rate. Also, the accurate ullage volume is not known but based on load sensors whose measurements were observed to wander during the test, and an assumed constant propellant density.

\section{Integrated Model}

As of writing this paper, test data with an IVF loop were not available, therefore verification of the integrated model was limited to the parametric study to investigate the effect of a few pertinent input parameters on the performance of the IVF system. The input parameters chosen for this study are: a) coolant inlet temperature in the heat exchanger, b) input power to the blower, and c) coolant flow rate in the heat exchanger. The five cases that were run are shown in Table 2.

Figure 21 shows the predicted pressure history at ullage, blower inlet, and heat exchanger outlet. It may be noted that predicted pressure rise in the blower is about $13.7 \mathrm{psi}$ and pressure drop in the heat exchanger is about 4.7 psi at the end of a 200 -s simulation. Figure 22 shows a predicted temperature rise in the blower and heat exchanger. The temperature rise in the blower is on the order of $50{ }^{\circ} \mathrm{F}$ during the 200 -s simulation period, and slowly increases due to a reduction in flow rate (see Fig. 26). The temperature rise in the heat exchanger dropped from 80 to $30^{\circ} \mathrm{F}$ during this period because the inlet temperature in the heat exchanger continuously rises as ullage is becoming warmer due to pressurization. Predicted ullage pressure history for all cases is shown in Fig. 23. Tank pressurization is a strong function of blower power. The effect of

Table 2. Input parameters for the parametric study.

\begin{tabular}{cccc}
\hline $\begin{array}{c}\text { Case } \\
\text { Number }\end{array}$ & $\begin{array}{c}\text { Coolant } \\
\text { Temperature } \\
\left({ }^{\circ} \text { F) }\right.\end{array}$ & $\begin{array}{c}\text { Blower } \\
\text { Power } \\
(\text { HP) }\end{array}$ & $\begin{array}{c}\text { Coolant } \\
\text { Flow Rate } \\
(\mathbf{l b} / \mathbf{s})\end{array}$ \\
\hline 1 & 120 & 8.8 & 6.64 \\
2 & 100 & 8.8 & 6.64 \\
3 & 120 & 5.0 & 6.64 \\
4 & 120 & 12.0 & 6.64 \\
5 & 120 & 8.8 & 4.01 \\
\hline
\end{tabular}
coolant flow rate and temperature on tank pressurization is relatively insignificant. Figure 24 shows the predicted temperature rise in the blower for all cases. Temperature rise is a strong function of blower input power. The effect of coolant flow rate and temperature is insignificant. A predicted temperature rise in the heat exchanger, shown in Fig. 25, is a strong function of flow rate in the IVF loop. The predicted flow rate variation is shown in Fig. 26, which also shows its dependency on blower input power. 


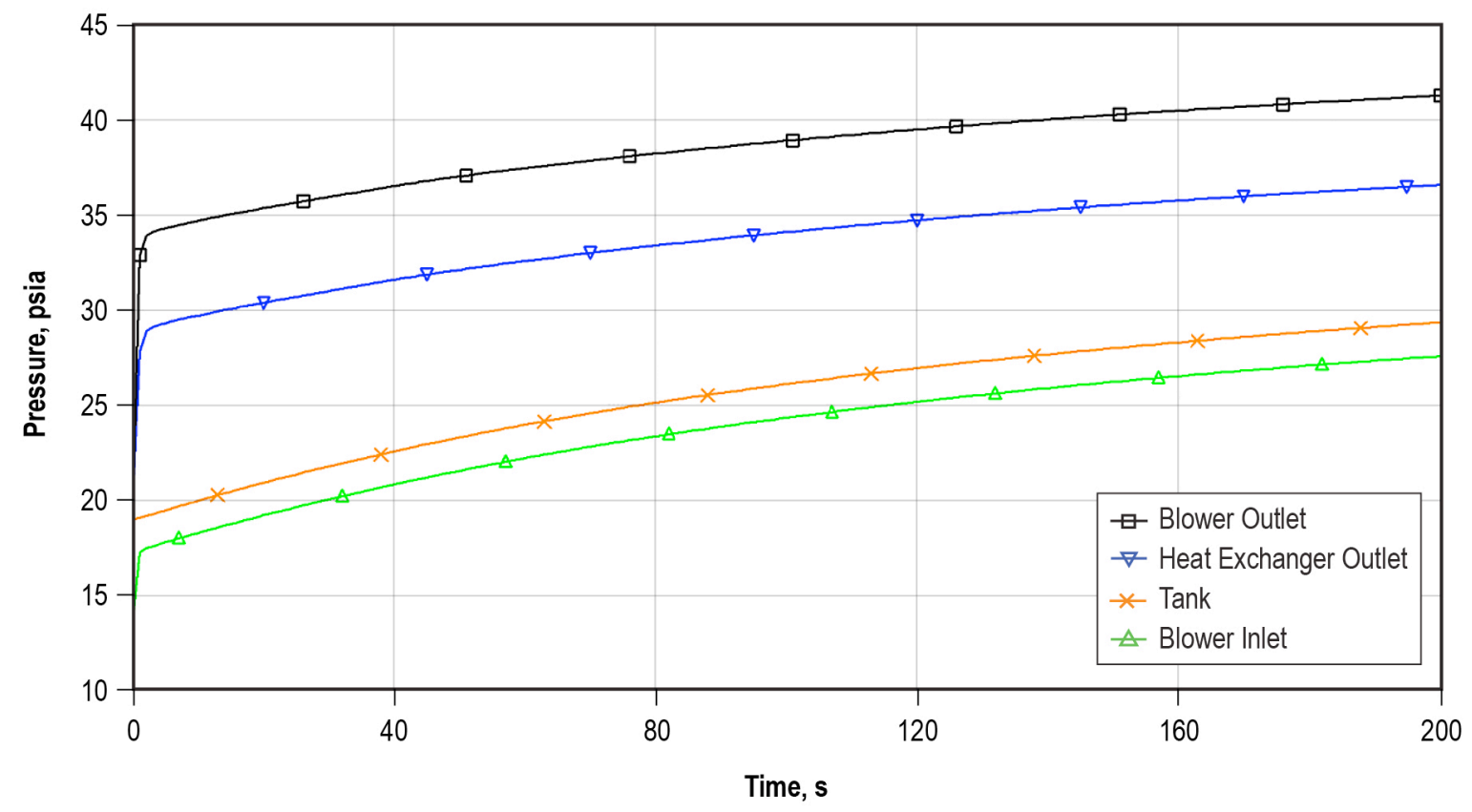

Figure 21. Predicted pressure history in tank and IVF loop for case 1.

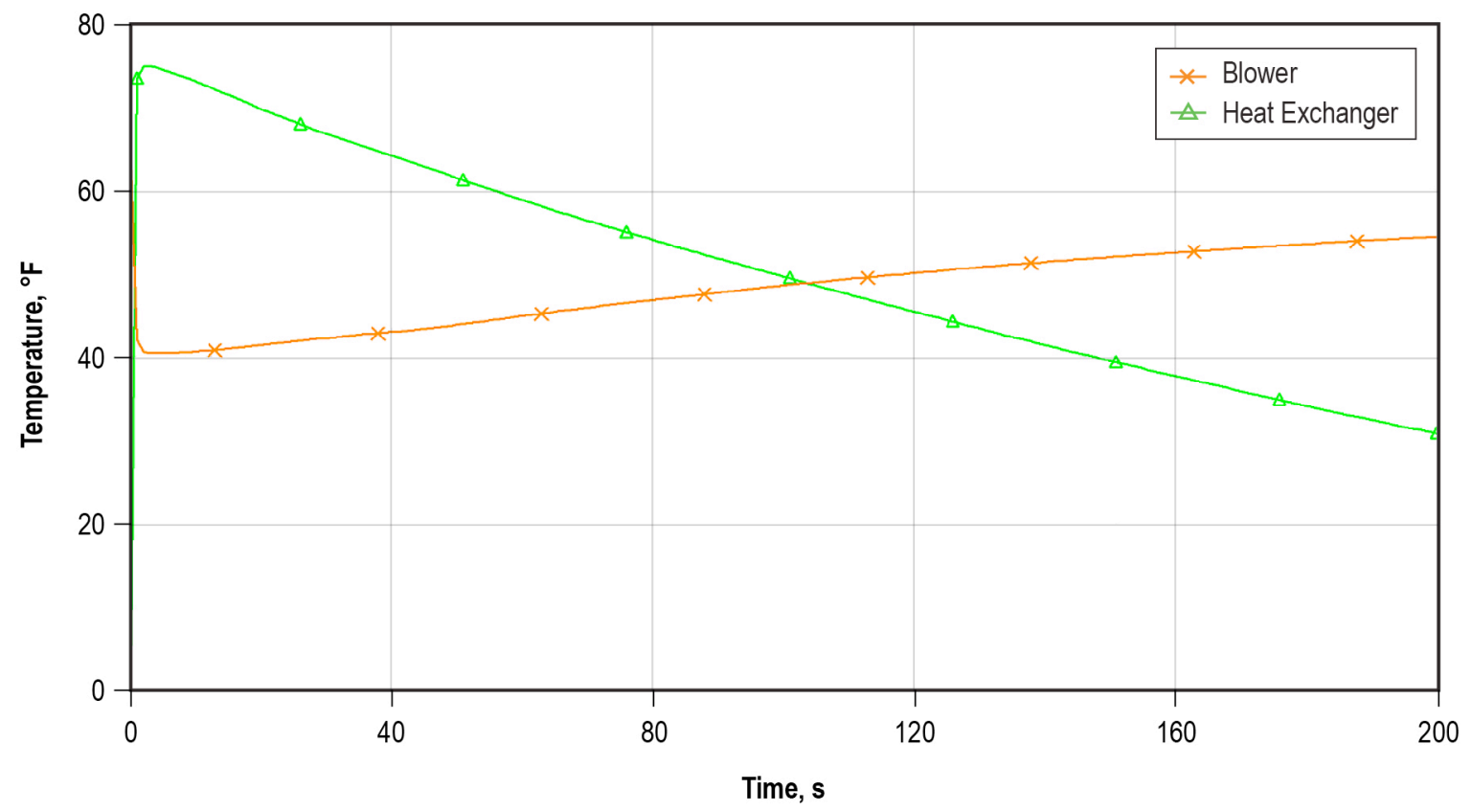

Figure 22. Predicted temperature rise in blower and heat exchanger for case 1. 


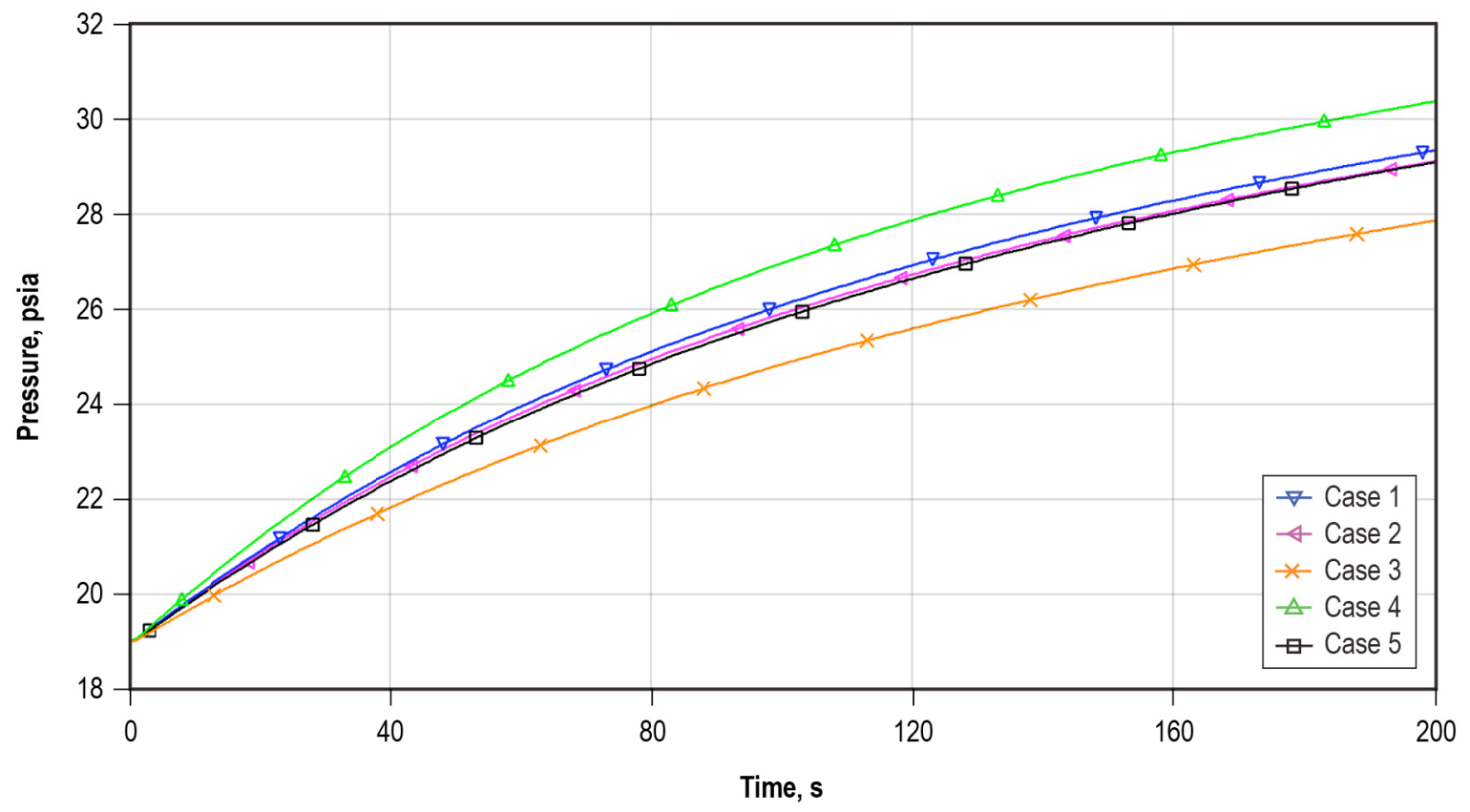

Figure 23. Predicted ullage pressure history for all cases.

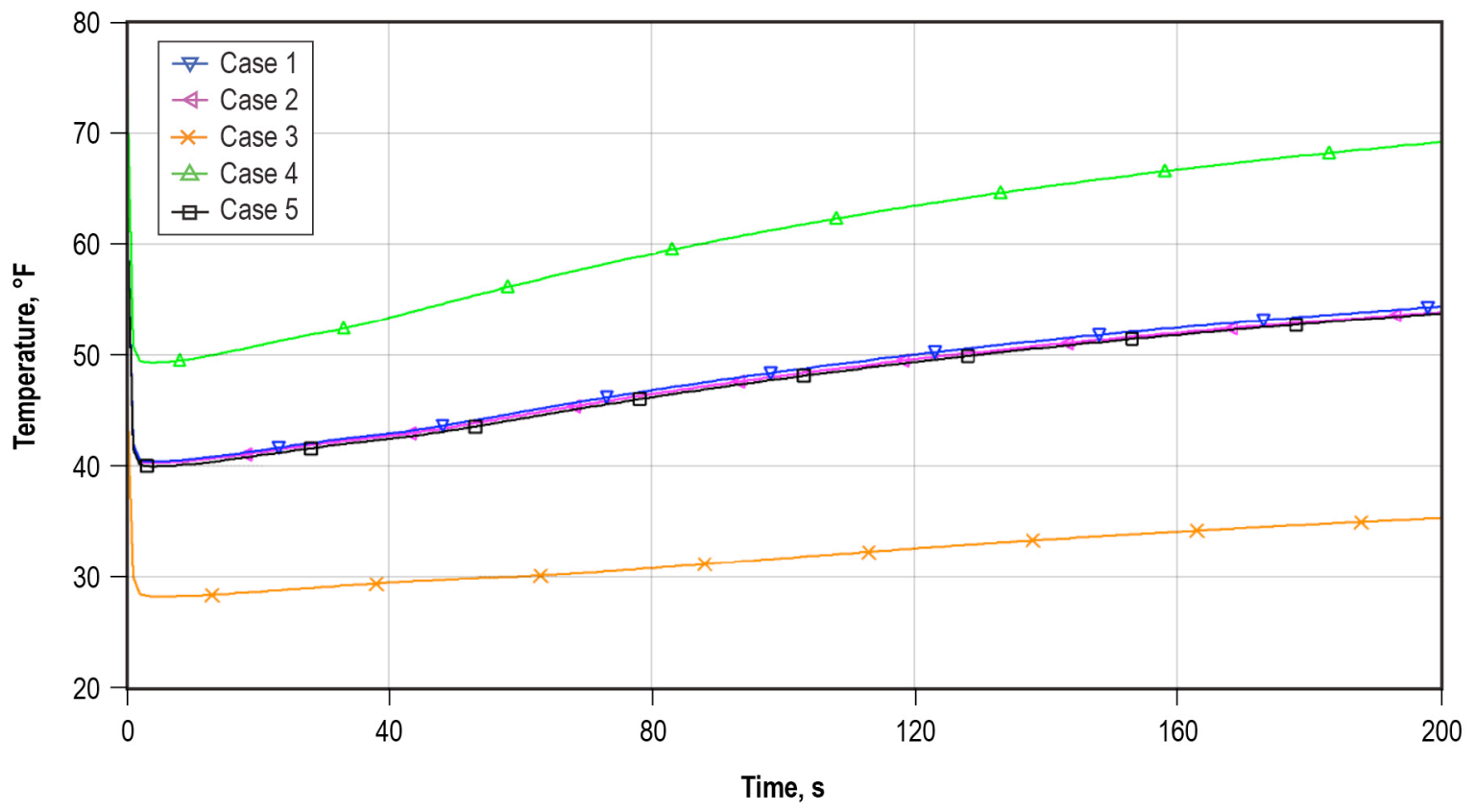

Figure 24. Predicted temperature rise in blower for all cases. 


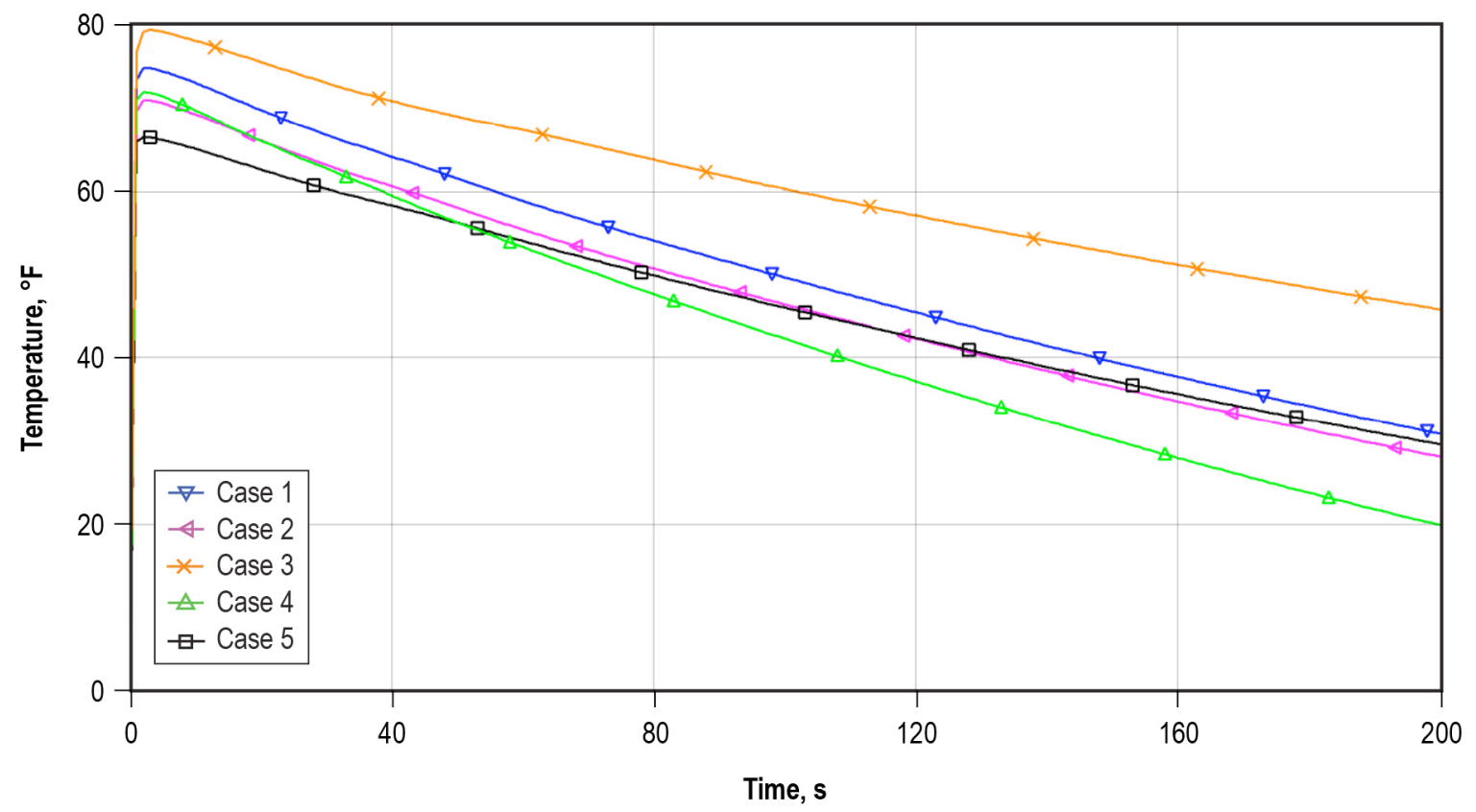

Figure 25. Predicted temperature rise in heat exchanger for all cases.

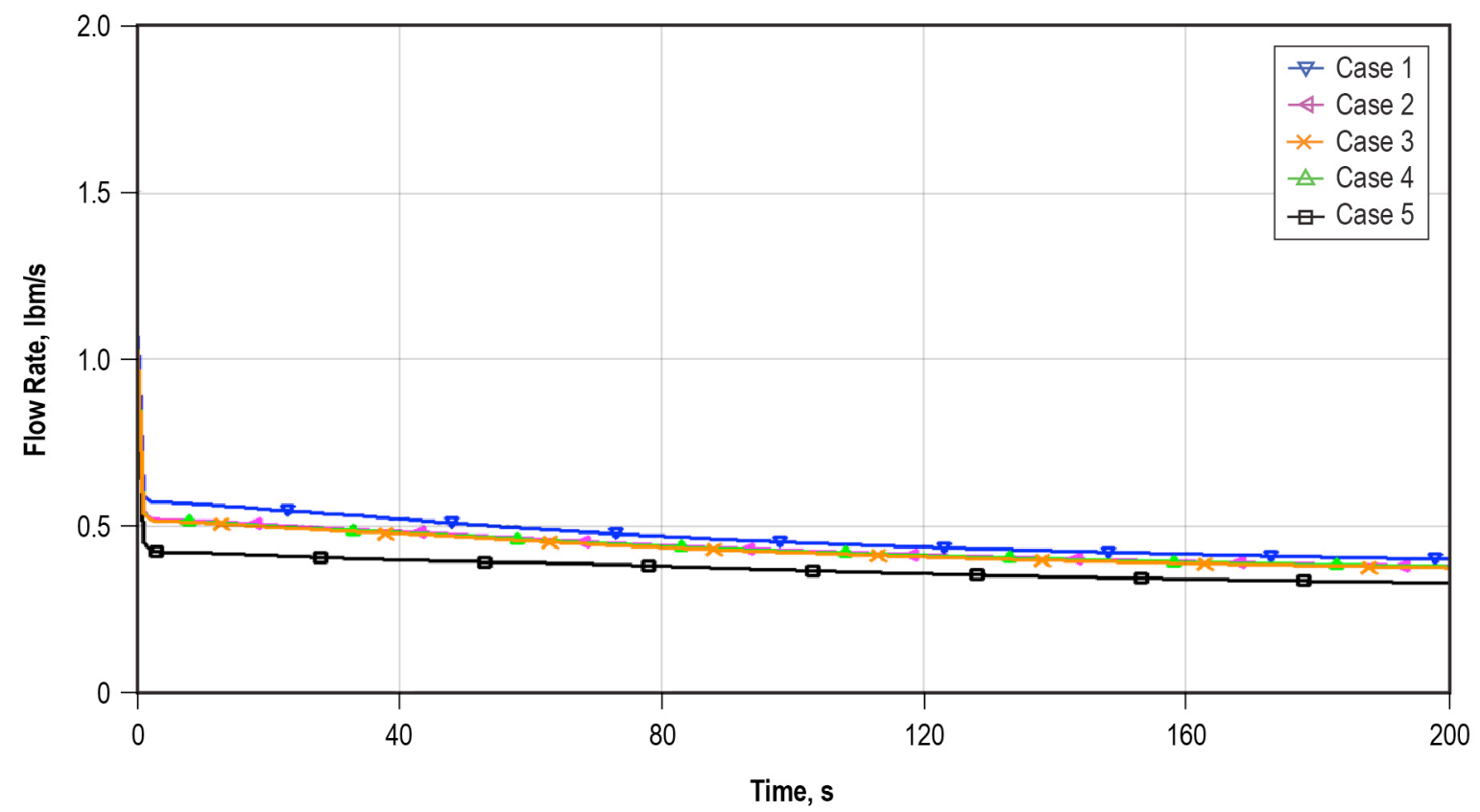

Figure 26. Predicted flow rates in the IVF loop for all cases. 


\section{Conclusion}

This paper presents a multinode model of ullage space of a cryogenic tank. The ullage space was modeled as two concentric cylinders: one representing the core and the other representing the boundary layer. Each cylinder was discretized vertically and also connected radially to allow a recirculating flow caused by stratification. The model predictions of boiloff and pressurization have been compared with measured data. The agreement between measurements and predictions is reasonable. The observed discrepancies are likely due to the uncertainty of the heat transfer coefficient and not accounting for the thermal capacitance of additional hardware in the tank (diffuser and camera).

The paper also presents a unique method of integration of a system (tank and IVF loop) and component (heat exchanger) model where two models exchange data during an iterative cycle of the simulation. In each time step, the interface boundary condition is adjusted until convergence. The parametric study of the integrated model demonstrates the sensitivity of the pertinent input parameters, such as blower input power, coolant flow rate, and temperature, on the performance of the pressurization system.

\section{Acknowledgments}

The authors wish to acknowledge NASA Space Technology Mission Directorate's Evolvable Cryogenics project for supporting this investigation. Thanks are due to Arthur Werkheiser, Monica Guzik, Jonathan Stephens, and Juan Valenzuela for their valuable input to the current investigation. The authors also acknowledge Marvin Rocker and STI Publications for their contribution.

\section{References}

${ }^{1}$ Zegler, F., “An Integrated Vehicle Propulsion and Power System for Long Duration Cryogen Spaceflight,” AIAA 20117355, AIAA SPACE 2011 Conference \& Exposition, September 27-29, 2011, Long Beach, CA, http://dx.doi.org/10.2514/ $6.2011-7355$

${ }^{2}$ Majumdar, A. K., LeClair, A. C., Moore, R., and Schallhorn, P. A., "Generalized Fluid System Simulation Program, Version 6.0," NASA/TP-2016-218218, March 2016.

${ }^{3}$ Majumdar, A. K., and Steadman, T., "Numerical Modeling of Pressurization of a Propellant Tank," Paper No. AIAA 990879, 37th AIAA Aerospace Sciences Meeting Conference and Exhibit, Reno, NV, January 11-14, 1999; Journal of Propulsion and Power, Vol. 17, No. 2, March-April 2001, http://dx.doi.org/10.2514/2.5754.

${ }^{4}$ Steadman, T., Majumdar, A. K., and Holt, K., "Numerical Modeling of Helium Pressurization System of Propulsion Test Article (PTA)," 10th Thermal Fluid Analysis Workshop, Huntsville, AL, September 13-17, 1999, NASA/CP-2001-211141, July 2001, 13 pp.

${ }^{5}$ Majumdar, A., Valenzuela, J., LeClair, A., and Moder, J., "Numerical modeling of self-pressurization and pressure control by a thermodynamic vent system in a cryogenic tank," Cryogenics, Vol. 74, March 2016, pp. 113-122.

${ }^{6}$ Rohsenow, W. M., Hartnett, J. P., and Cho, Y. I.: Handbook of Heat Transfer, $3^{\text {rd }}$ ed., McGraw-Hill, 1998, p. 4.13. 